\title{
Latenciação e formas avançadas de transporte de fármacos
}

\author{
Man-Chin Chung ${ }^{1 *}$, Antonio Távora de Albuquerque Silva', Lúcia Fioravanti Castro', Rafael \\ Victório Carvalho Güido' ${ }^{1}$ José Carlos Nassute' ${ }^{1}$ Elizabeth Igne Ferreira²
}

${ }^{1}$ Lapdesf - Laboratório de Pesquisa e Desenvolvimento de Fármacos, Departamento de Fármacos e Medicamentos,

Faculdade de Ciências Farmacêuticas, UNESP, ${ }^{2}$ Lapen - Laboratório de Planejamento e Síntese de Quimioterápicos Potencialmente Ativos em Endemias Tropicais, Departamento de Farmácia, Faculdade de Ciências Farmacêuticas, USP/SP

*Correspondence:

Man-Chin Chung

FCF/UNESP

Rod. Araraquara-Jaú, KM-1

14801-902, Araraquara, SP

E-mail: chungmc@fffar.unesp.br
O processo de modificação molecular denominado latenciação é revisto, apresentando formas avançadas no transporte de fármacos, utilizando macromoléculas como transportadores e sistemas de liberação sítio-específica como: CDS (Chemical Delivery System), ADEPT (Antibody-Directed Enzyme Prodrug Therapy), GDEPT/ VDEPT (Gene-Directed Enzyme Prodrug Therapy/Virus-Directed Enzyme Prodrug Therapy), ODDS (Osteotropic Drug Delivery System), PDEPT (Polymer-Directed Enzyme Prodrug Therapy), PELT (Polymer-Enzyme Liposome Therapy) e LEAPT (LectinDirected Enzyme-Activated Prodrug Therapy).
Uniterms

- Latenciação

- Pró-fármacos

- Transportadores macromoleculares

- Sistemas de liberação específica

\section{INTRODUÇÃO}

Existem, ainda, diversos fármacos (alguns muito potentes) com características físico-químicas, organolépticas, farmacocinéticas, farmacológicas e toxicológicas, que se caracterizam como barreiras para sua aplicação clínica (Zheng et al., 1999; Han, Amidon, 2000; Ettmayer et al., 2004).

Para otimizar as propriedades físico-químicas de um fármaco, podem-se derivar certos grupos funcionais polares através de processo biorreversível com pequenas moléculas orgânicas, mascarando tais características sem alterar permanentemente as propriedades da molécula. Tal estratégia tem sido aplicada com sucesso a grupos funcionais como álcoois, que, convertidos em ésteres, podem ser regenerados in vivo por via química ou enzimática. Este processo é denominado latenciação de fármacos (Chung, Ferreira, 1999; Zheng et al., 1999; Ettmayer et al., 2004). O termo latente significa presente ou existente, mas não manifestado, exibido ou desenvolvido.
A latenciação de fármacos foi proposta, em 1959, por Harper, e consiste, basicamente, na transformação do fármaco em forma de transporte inativo, que, in vivo, mediante reação química ou enzimática, libera a porção ativa no local de ação ou próximo dele. Entretanto, somente em meados da década de 1970, quando pesquisadores começaram a localizar os alvos dos fármacos no organismo e compreender a farmacocinética dos mesmos, é que o processo de latenciação tomou direção mais definida (Chung, Ferreira, 1999; Han, Amidon, 2000).

Em 1958, Adrien Albert definiu pró-fármacos como qualquer composto que sofre biotransformação antes de exibir seus efeitos farmacológicos (Friis, Bundgaard, 1996; Chung, Ferreira, 1999; Wermuth, 2003; Ettmayer et al., 2004). Definição expandida considera um pró-fármaco como um fármaco ativo, quimicamente transformado em um derivado inativo, que é convertido por um ataque químico ou enzimático ou de ambos no fármaco matriz no organismo, antes ou após alcançar seu local de ação (Figura 1).

O fármaco latente é uma espécie de "Cavalo de 


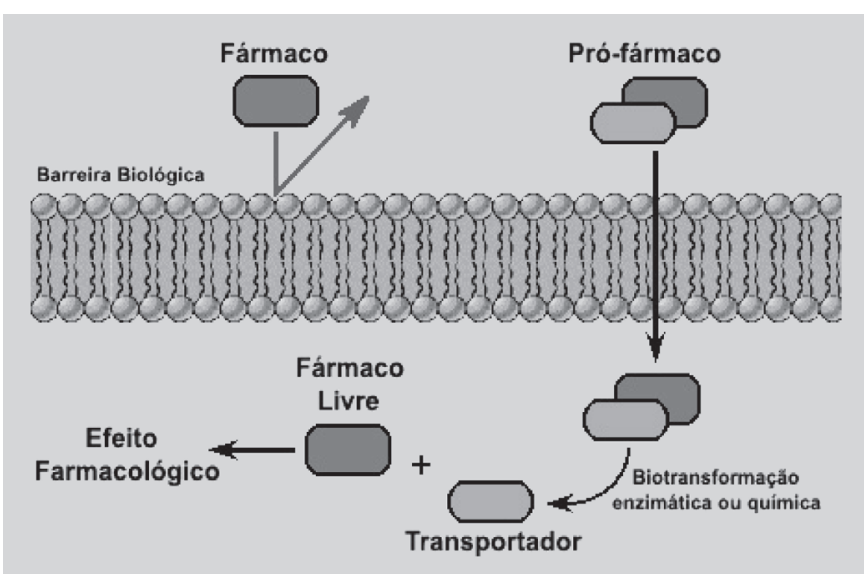

FIGURA 1 - Representação esquemática do conceito de pró-fármaco (adaptado de Bundgaard, 1985)

Tróia", uma vez que engana o organismo. No entanto, diferentemente deste, não tem o objetivo de destruí-lo e sim de ajudá-lo. Várias substâncias ativas "blockbusters" (Figura 2), isto é, campeões em vendas no mercado mundial, são prófármacos, demonstrando a importância desta estratégia no planejamento de fármacos (Ettmayer et al., 2004).

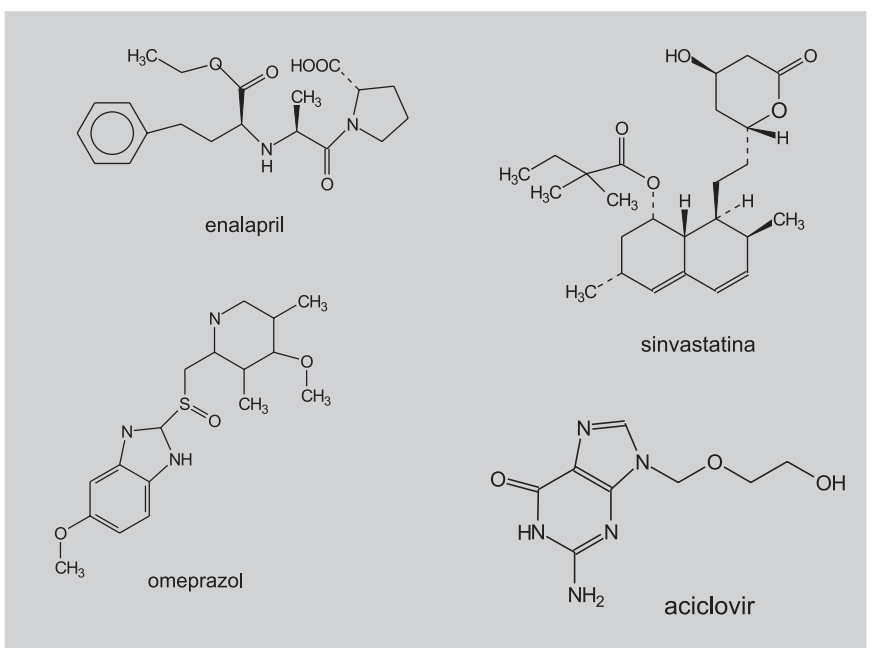

FIGURA 2 - Alguns pró-fármacos "blockbuster" (Ettmayer et al., 2004)

Muitas razões relacionadas ao fármaco matriz justificam a necessidade de modificação molecular por meio da latenciação e são elas (Friis, Bundgaard, 1996; Chung, Ferreira, 1999; Wermuth, 2003; Choi, Jo, 2004; Skoblov et al., 2004; Silva et al., 2005):

1. Problemas farmacocinéticos, como a baixa biodisponibilidade oral (devido à polaridade e/ou solubilidade); distribuição insuficiente no local de ação e/ou incapacidade de atravessar diversos tipos de barreiras biológicas (mucosa gástrica, pele, córnea e barreira hematoencefálica), que separam o fármaco de seu local de ação;

2. Elevada toxicidade;

3. Baixa estabilidade química;

4. Odor e paladar inconvenientes;

5. Dor no local da administração;

6. Formulação farmacêutica de difícil preparo.

Para permitir este aprimoramento das propriedades do fármaco matriz, os pró-fármacos devem possuir características importantes, tais como (Friis, Bundgaard, 1996; Chung, Ferreira, 1999; Ettmayer et al., 2004):

1. Inatividade ou menor atividade do que o fármaco matriz;

2. Obtenção por síntese menos complexa que a do fármaco matriz, sempre que possível.

3. Ligação entre o fármaco matriz e o transportador cindida, in vivo, por via química ou enzimática;

4. Falta de toxicidade do transportador;

5. Cinética adequada de biotransformação direta tanto quanto de inativação, assegurando níveis eficazes do fármaco no local de ação.

O desenvolvimento de pró-fármacos tem como objetivo resolver diversos problemas relacionados aos fármacos, como baixa biodisponibilidade, toxicidade, falta de seletividade e instabilidade, entre outros (Friis, Bundgaard, 1996; Chung, Ferreira, 1999; Ettmayer et al., 2004).

Os principais grupos reversíveis utilizados no planejamento de pró-fármacos encontram-se arrolados em Friis e Bundgaard (1996), como por exemplo ésteres, amidas, carbamatos, fosfatos entre outros.

\section{CLASSIFICAÇÃO DE PRÓ-FÁRMACOS}

Wermuth, em 1984, classificou as formas latentes em pró-fármacos, subdivididos em pró- fármacos clássicos, bioprecursores, mistos e fármacos dirigidos. A principal característica que diferencia essas duas categorias é a forma de transporte.

\section{Bioprecursores}

São fármacos latentes, que não apresentam um transportador propriamente dito, pois são moléculas inativas, que sofrem biotransformação (geralmente pelo sistema redox), in vivo, para transformar-se em metabólito ativo.

A lovastatina é inibidor da enzima HMG-CoA (3hidroxi-3-metilglutaril-coenzima-A redutase), utilizado no tratamento das hipercolesterolemias (Williams, Lemke, 2002) e ativo graças à biotransformação ao composto nãolactônico (Figura 3).

Outros fármacos comercializados são classificados 


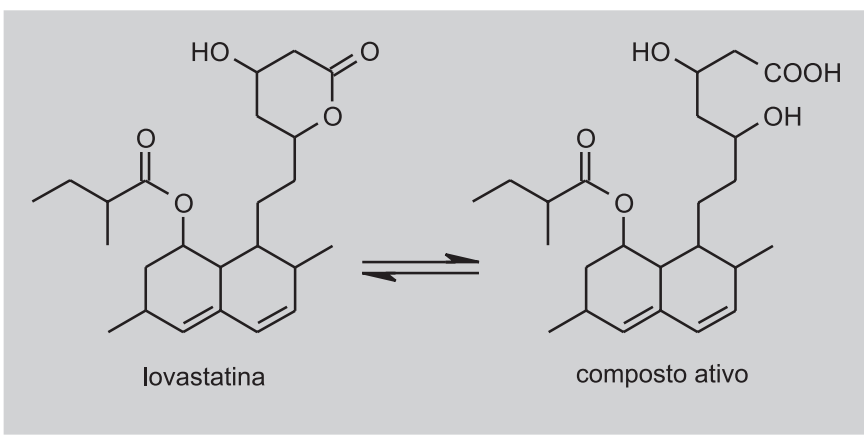

FIGURA 3 - Lovastatina e o derivado não-lactônico ativo.

em bioprecursores, como por exemplo, zidovudina (AZT), metronidazol, enalapril, aceclofenaco (Williams, Lemke, 2002). Pró-fármacos fotossensibilizadores utilizados em terapia fotodinâmica (PDT- photodinamic therapy) para o tratamento de câncer também são classificados como bioprecursores (Brown et al., 2004).

A estratégia da PDT é conhecida há mais de 25 anos, porém, somente há poucos anos ressurgiu na clínica. Entre os pró-fármacos sensibilizadores aprovados para utilização em oncologia, encontram-se os derivados de hematoporfirina (porfimero sódico) (Figura 4) ativos contra câncer de pulmão, câncer gástrico superficial, adenocarcinoma esofágico, câncer cervical e de bexiga; metiltetraidroxifenilclorina (temoporfina), ativo contra câncer de cabeça e pescoço; ácido 5-aminolevulínico (Figura 5), contra queratose actínica, e metil 5aminolevulinato, ativo contra queratose actínica, carcinoma de células basais, incluindo as superficiais (Brown et al., 2004; Detty et al., 2004; Gold, Goldman, 2004).

Estes compostos sensibilizadores absorvem a energia diretamente da fonte de luz (comprimento de onda que

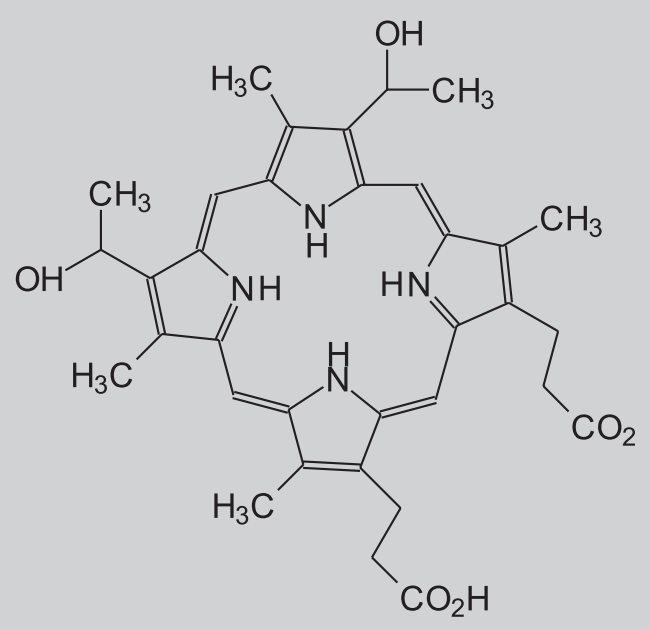

FIGURA 4 - Hematoporfirina, primeiro fotossensibilizador aprovado para terapia fotodinâmica (Detty et al., 2004).

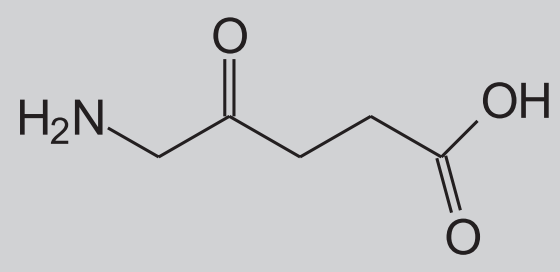

FIGURA 5 -Ácido aminolevulínico.

varia de 600 a $800 \mathrm{~nm}$ ), que é transferida ao oxigênio molecular, que gera um oxigênio singleto. Este promove a citotoxicidade, causando a morte do tecido tumoral. Durante este processo, o agente sensibilizador é regenerado, agindo novamente. Trata-se, portanto, de um ciclo, isto é, um sensibilizador atua em várias etapas da produção de oxigênio singlete (Brown et al., 2004; Detyy et al., 2004). Vários derivados têm sido propostos, sintetizados e encontram-se em fase de pesquisa clínica (Brown et al., 2004; Detty et al., 2004).

\section{Pró-fármacos clássicos}

Estes seguem a definição clássica de latenciação sendo, por si só, inativos ou menos ativos que o fármaco matriz, devendo sofrer hidrólise (química ou enzimática) para liberar a porção ativa.

Os pró-fármacos clássicos são obtidos mediante ligação do fármaco matriz a um transportador adequado, com o objetivo de melhorar as propriedades físico-químicas e, conseqüentemente, a atividade terapêutica, graças ao aumento da biodisponibilidade, da seletividade, à redução da toxicidade e ao prolongamento da ação (Steffansen et al., 2004).

O conhecimento de sistemas metabólicos no organismo é essencial para o planejamento de pró-fármacos. Neste sentido, Liao e Wang, em 1999, desenvolveram sistema de transporte baseado em cumarina, sensíveis a esterase (Figura 6), obtendo pró-fármacos com aumento significativo nos níveis de liberação da molécula matriz.

A hidrossolubilidade pode ser aumentada mediante diminuição das ligações de hidrogênio intra e/ou intermoleculares (Bundgaard, 1985), uma vez que estas con-

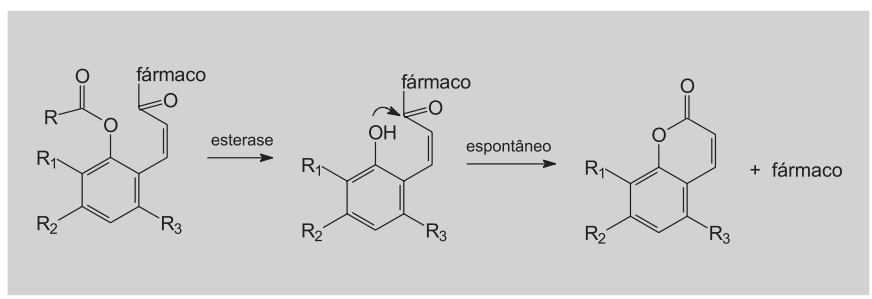

FIGURA 6 - Sistema desenvolvido por Liao e Wang (1999), sensível a esterase, baseado na cumarina. 
duzem a estruturas mais arranjadas, mais dificilmente solubilizadas em meio aquoso. Derivados hidroximetilados de fármacos ácidos, como amidas, permitem o aumento da hidrossolubilidade e se constituem em intermediários para ésteres.

Chung, em 1996, sintetizou o derivado hidroximetilado do nitrofural (NFOH) (Figura 7), como intermediário da síntese de pró-fármacos recíprocos de primaquina e nitrofurazona, potencialmente ativos em doença de Chagas. Tal composto mostrou-se altamente ativo, quando ensaiado em cultura de células infectadas com T. cruzi, e menos mutagênico, quando submetido ao teste de Ames, em comparação ao composto matriz (Güido et al., 2001; Chung et al., 2003).<smiles>O=C(NCO)N/N=C/C1=CC=C([N+](=O)[O-])C1</smiles>

FIGURA 7 - Derivado hidroximetilado do nitrofural (NFOH).

Pequenas moléculas, como os açúcares, aminoácidos ou peptídios, podem ser utilizadas como transportadores, para melhorar a biodisponibilidade por aumento da hidrossolubilidade (Han, Amidon, 2000). Além disso, estas moléculas têm sido utilizadas, também, como transportadores com o objetivo de diminuir a toxicidade (Clerici et al., 1994; Nishida et al., 1994; Vitols et al.., 1995; Chung et al., 1997; Ettmayer et al., 2004; Vabeno et al., 2004). A utilização de peptídios como transportadores surgiu de trabalhos de Carl e colaboradores (1980), com o objetivo de diminuir a toxicidade de fármacos altamente tóxicos, como os antineoplásicos.

Os ácidos 7-cloroquinurênico e 5,7dicloroquinurênico são potentes antagonistas de receptor glicina-NMDA, cuja captação cerebral foi aumentada por latenciação destes sob forma de pró-fármacos utilizando aminoácidos como transportadores (Han, Amidon, 2000).

Por outro lado, Aviva e colaboradores (2000) sintetizaram pró-fármacos peptídicos de alendronato e de pamidronato (Figura 8), com o objetivo de aumentar a absorção oral. Observou-se alta afinidade destes prófármacos pelo tecido intestinal, além de transporte mais eficiente do que o fármaco matriz através das células Caco-2, resultando em biodisponibilidade oral 3 vezes maior em comparação ao fármaco matriz.

Jarkko e colaboradores (2000) desenvolveram diversos pró-fármacos de naproxeno sob a forma de ésteres metilpiperazinilaciloxialquílicos (3c-f) (Figura 9), com a finalidade de uso tópico. Tais compostos apresentaram alta

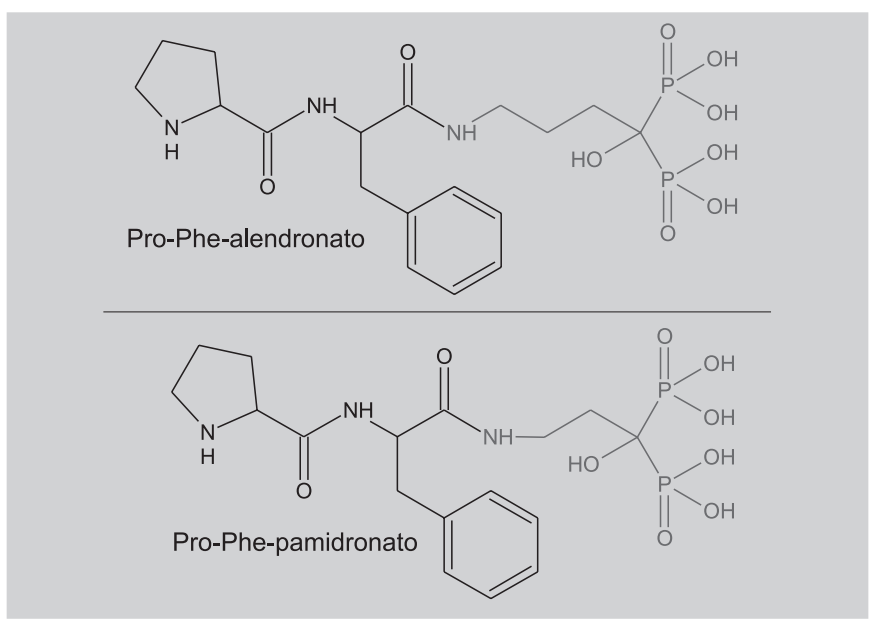

FIGURA 8 - Pró-fármacos dipeptídicos de bisfosfonatos sintetizados por Aviva et al. (2000).

hidrossolubilidade e lipofilicidade semelhante ao naproxeno em $\mathrm{pH}$ 5,0. Em pH 7,4, esses mesmos compostos foram significativamente mais lipofílicos que o naproxeno. O prófármaco $3 \mathrm{c}$ mostrou-se mais promissor, com capacidade de permeabilidade cutânea de 1,5 a 4 vezes maior que a do naproxeno em pH 5,0 e 7,4, respectivamente. Esses autores mostraram que a característica de solubilidade bifásica e a rápida hidrólise enzimática dos derivados metilpiperazinilaciloxialquílicos aumentam a permeabilidade cutânea (liberação) do naproxeno.

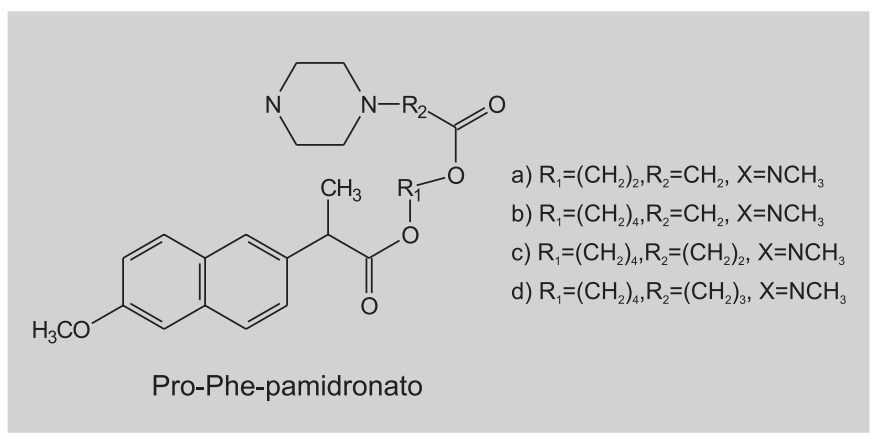

FIGURA 9. Pró-fármacos dipeptídicos derivados de naproxeno (Jarkko et al., 2000).

O valaciclovir é um pró-fármaco do aciclovir, que apresenta absorção aumentada em cerca de 3 a 5 vezes em relação ao fármaco matriz. In vivo, é rapidamente absorvido pelo trato gastrintestinal e biotransformado em aciclovir (Ettmayer et al., 2004)

Utilizando abordagem análoga, Nashed e Mitra (2003) sintetizaram série de novos derivados dipeptídicos de aciclovir solúveis utilizando como alvo o sistema de transporte peptídico da córnea e células epiteliais intestinais, com o objetivo de melhorar, respectivamente, a absorção ocular e oral no tratamento do herpes. Em 2004, 
Skoblov e colaboradores demonstraram que todos os prófármacos sintetizados são hidrolisados em aciclovir.

A utilização de ésteres fosfato de derivados alcoxílicos é, também, forma muito empregada para o aumento da hidrossolubilidade, especialmente com vistas ao uso por via parenteral (Friis, Bundgaard, 1996; Ettmayer et al., 2004), como por exemplo a fosfenitoína, planejada a partir da fenitoína, anticonvulsivante insolúvel para uso parenteral (Boucher et al., 1989; Ettmayer, et al., 2004).

Baker e colaboradores (2004) sintetizaram série de pró-fármacos de fluorquinolonas com o intuito de aumentar a hidrossolubilidade para as administrações intravenosa e inalatória, tendo-se obtido melhores resultados com o composto PA2808 (figura 11).

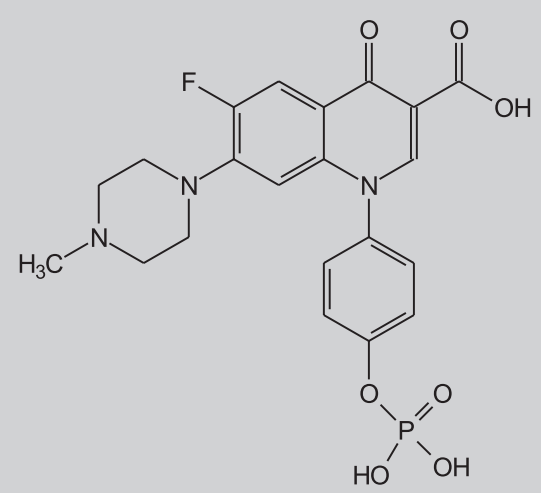

FIGURA 11 - Pró-fármaco hidrossolúvel PA 2808, derivado de fluorquinolona (Baker et al., 2004).

O paclitaxel é potente antitumoral utilizado no tratamento de leucemia, tumores sólidos de mama, ovário, cérebro e pulmões. Por ser altamente lipofílico e insolúvel na água (hidrossolubilidade $<0,004 \mathrm{mg} / \mathrm{mL}$ ), é utilizado na terapêutica, parenteralmente juntamente com um veículo (Cremofor ${ }^{\mathbb{R}}$ ), tóxico, o que aumenta a toxicidade do tratamento com paclitaxel. Com o objetivo de resolver esse problema, Nicolaou e colaboradores (1993) sintetizaram vários pró-fármacos, sendo os compostos 1 e 2 , de hidrossolubilidade de 0,5 e $1,2 \mathrm{mg} / \mathrm{mL}$, respectivamente (Figura 12).

Entretanto, a estabilidade destes pró-fármacos deve ser considerada. Allen e colaboradores (2001) sintetizaram, então, pró-fármacos hidrossolúveis de paclitaxel, entre eles o protaxel (Figura 13), com características superiores àquelas obtidas por Nicolaou. Este derivado é estável em condições ácidas moderadas, sendo sua solução para uso clínico mais estável que a do paclitaxel e a tolerância sistêmica de 2,5 a 3 vezes maior que a do fármaco matriz. Além disso, mostrou-se

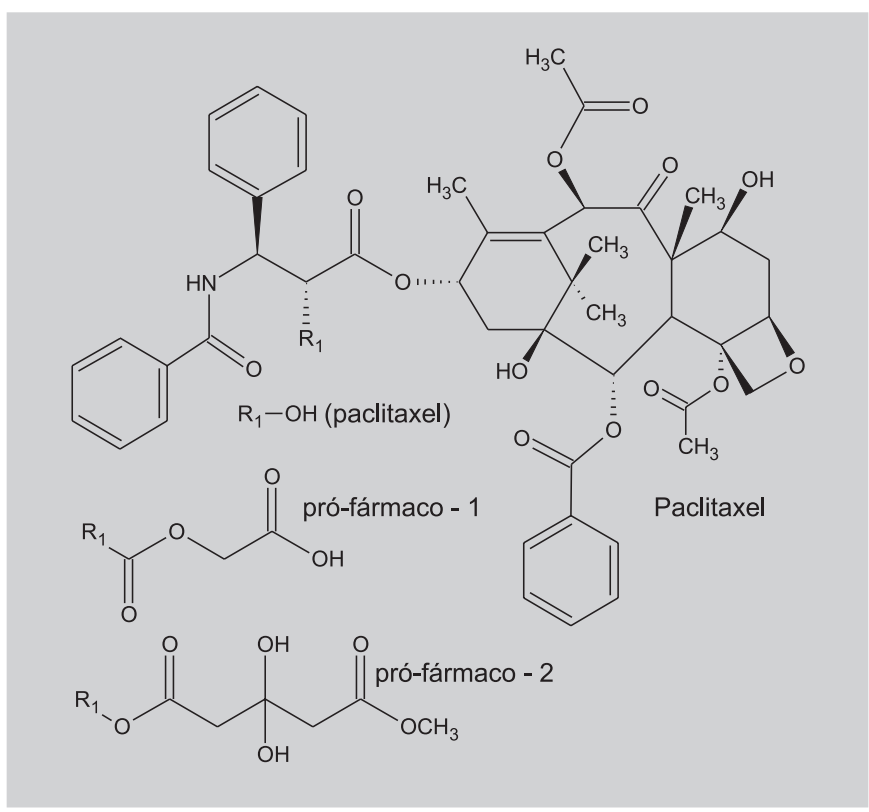

FIGURA 12 - Pró-fármacos do paclitaxel (Nicolaou et al., 1993).

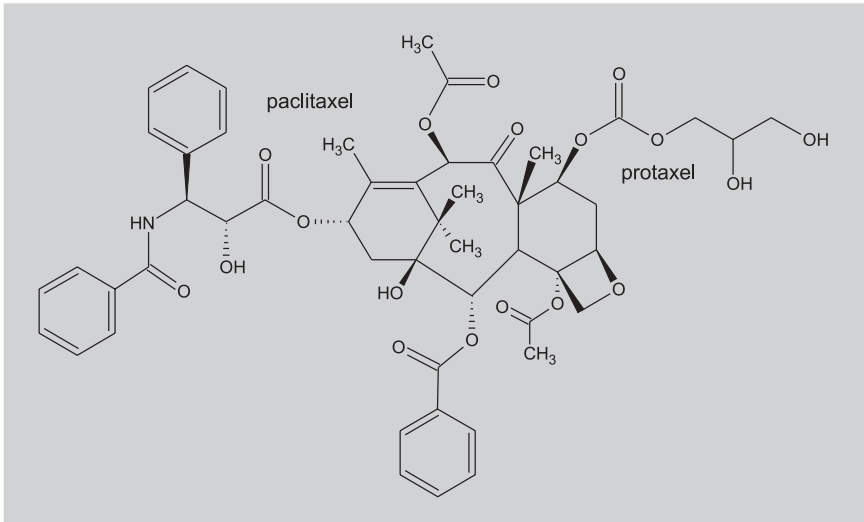

FIGURA 13 - Protaxel (Allen et al., 2001).

mais eficaz contra alguns tipos de câncer humano em modelo animal (camundongos).

A utilização de transportadores macromoleculares hidrossolúveis tem sido estudada por vários pesquisadores. Jo e Choi (2004) demonstraram o aumento da biodisponiblidade oral do pró-fármaco polimérico derivado de polietilenoglicol e paclitaxel (Figura 14), sintetizado por Jo

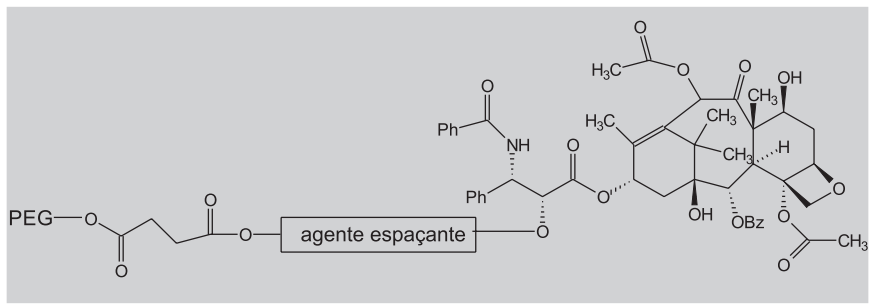

FIGURA 14 - Pró-fármaco polimérico derivado de paclitaxel-PEG-paclitaxel. 

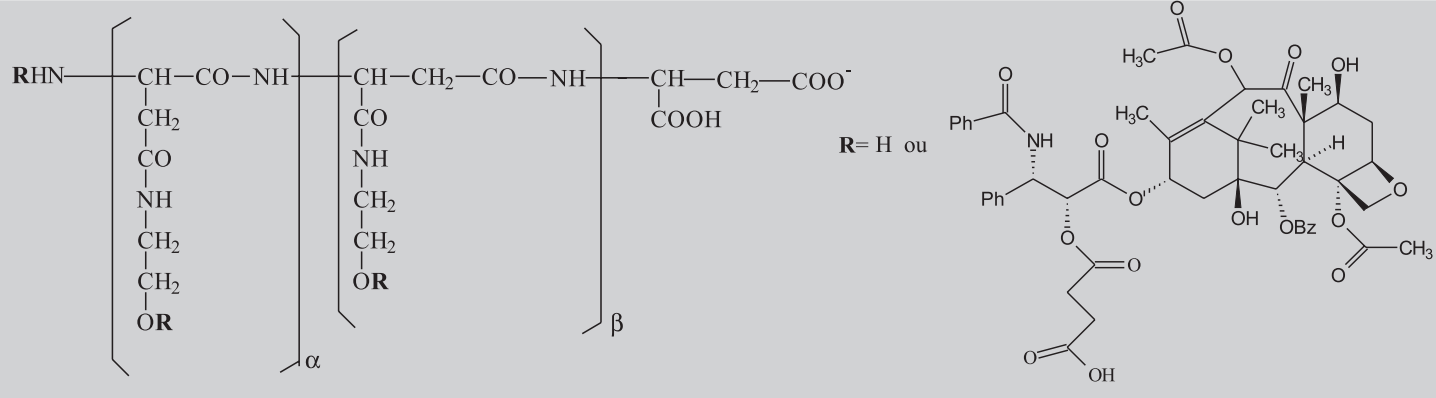

$2^{\prime}-O$-succinilpaclitaxel

FIGURA 15 - Pró-fármaco polimérico derivado de paclitaxel - PHEA-2'-O-succinil paclitaxel.

e colaboradores, em 2003, em relação ao paclitaxel, sugerindo a possibilidade de administração oral desse fármaco como pró-fármaco "peguilado".

Outro polímero foi utilizado por Cavalharo e colaboradores (2004) com o mesmo objetivo. Estes pesquisadores sintetizaram o pró-fármaco polimérico $[\alpha-\beta$-poli $(N-2-$ hidroxietil-DL-aspartamida)] 2-O-succinil paclitaxel (PHEA-2'-O-succinil paclitaxel) ( Figura 15)

\section{Pró-fármacos mistos}

Os pró-fármacos mistos constituem-se em formas latentes com características de bioprecursores e de prófármacos clássicos, isto é, apresentam-se como molécula biologicamente inativa, que necessita sofrer diversas reações químicas para se converter na forma ativa, aumentando a concentração do fármaco ativo em um sítio de ação específico. (Bodor, Abdelalim, 1985)

Exemplo desse tipo de pró-fármaco, que necessi- ta biotransformação do transportador previamente à liberação do fármaco é o sistema denominado CDS (Chemical Delivery System), idealizado por Bodor e Abdelalim, em 1985 (Figura 16), originalmente empregado para liberação específica no cérebro. Por esse sistema, o transportador é biotransformado após atravessar a barreira hematoencefálica (BHE), sofrendo, primeiramente, oxidação, tornando-se positivamente carregado e acumulando-se, dessa forma, no SNC, onde sofre, em seguida, reação de biotransformação para liberar o fármaco ativo (Prokai, Prokai, Tatrai, 2000).

Este sistema foi usado para o planejamento de vários fármacos antivirais para o tratamento da AIDS, como a zidovudina (AZT), utilizando o sistema 1,4diidroxitrigonelina-trigonelina como transportador (Figura 17) (Little et al., 1990; Brewster et al.., 1997) e análogos da didesoxiadenosina, no tratamento da encefalite provocada por herpes simplex, citomegalovirus e da encefalite viral japonesa.

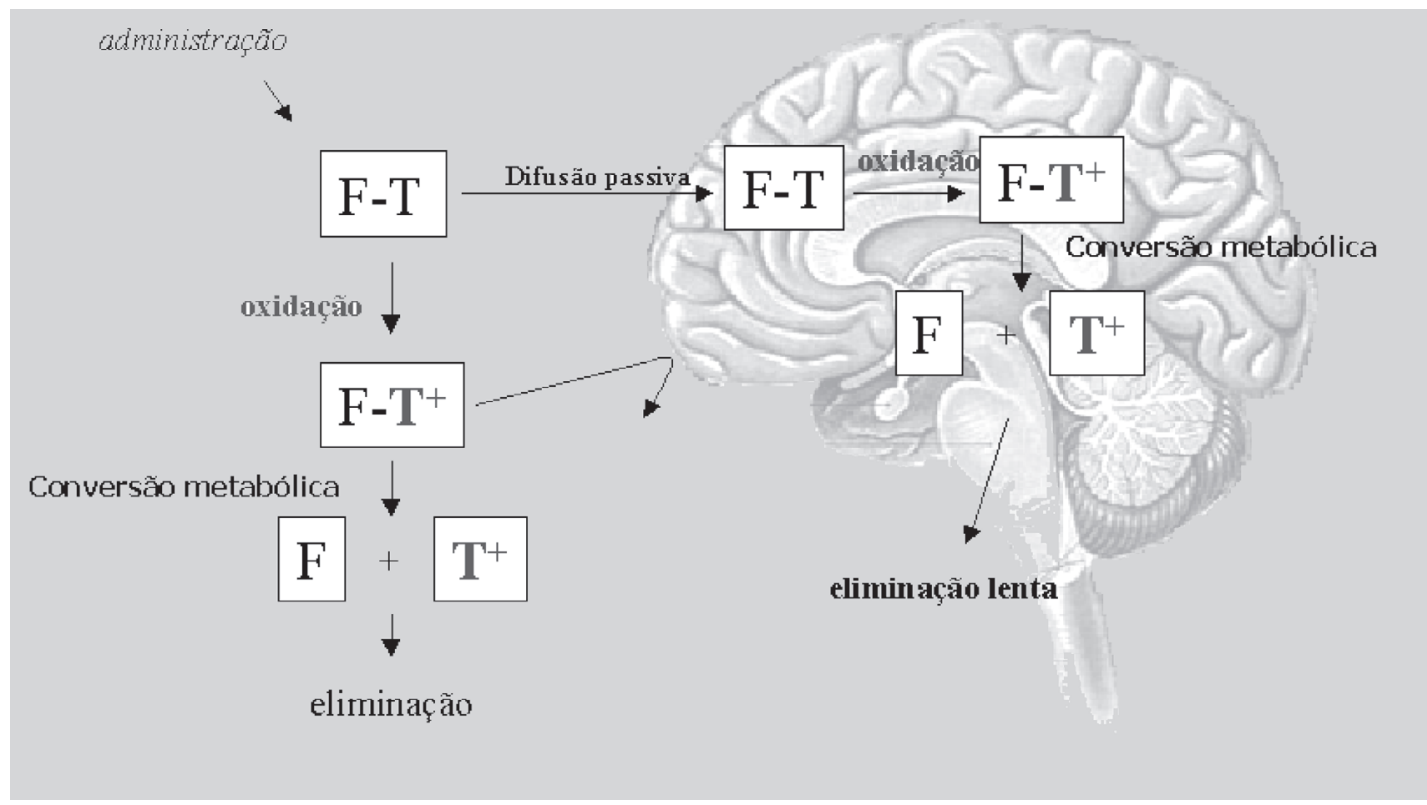

FIGURA 16 - Representação do Sistema CDS/SNC. 


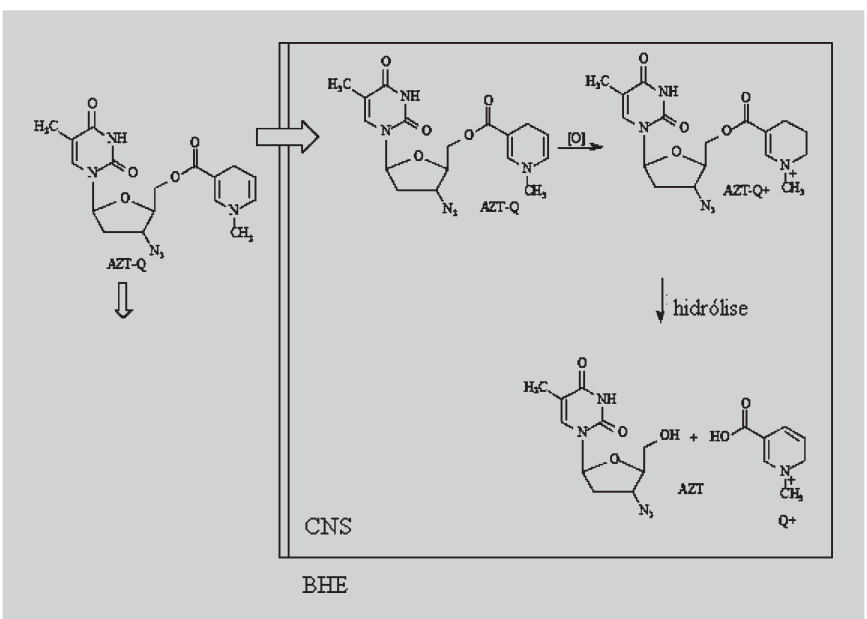

FIGURA 17 - Sistema AZT-CDS. A zidovudina foi acoplada ao transportador 1,4-diidrotrigonelina (AZT-Q), o qual é difundido para o SNC. O transportador sofre oxidação em trigonelina $(\mathrm{Q}+)$, acumulando-se no tecido cerebral. Em seguida, sofre hidrólise para a liberação do fármaco.

Outro transportador utilizado para o mesmo objetivo é o derivado (aciloxi)alquil fosfonato, denominado de sistema CDS aniônico, sintetizado por Somogyi e colaboradores, em 2002, também com o intuito de obter o acúmulo seletivo da zidovudina no SNC. Após administração, o pró-fármaco AZT-aCDS que atravessou a barreira hematoencefálica sofre hidrólise por esterases e, em seguida, decomposição rápida, espontânea, formando o AZT-P-, o qual é acumulado no SNC para posterior desfosforilação e liberação da molécula matriz de AZT (Figura 18). Em 2004, Somogyi e colaboradores revisaram as propriedades metabólicas de ésteres fosfonatos para o uso em latenciação.

Não apenas o SNC é alvo de estudo utilizando os sistemas CDS. Farag (1997) preparou pró-fármaco derivado de betaxolol para tratamento de glaucoma e, em 2001, Bodor e colaboradores sintetizaram pró-fármaco análogo de triptamina, com alta afinidade ao tecido cardíaco, para utilização como antiarrítmicos (Figura 19), utilizando sistema 1,4-diidroxitrigonelina-trigonelina como transportador do sistema CDS.

Para o tratamento da doença de Alzheimer (DA), Perioli e colaboradores (2004) sintetizaram vários prófármacos antiinflamatórios derivados de diclofenaco e do ibuprofeno (Figura 20), cetoprofeno, ácido tiaprofênico e tolmetina, utilizando sistema CDS/SNC e observaram, pelo estudo de $\log \mathrm{P}$, que os pró-fármacos derivados de diclofenaco e ibuprofeno contendo como agente espaçante (R1) uma cadeia propílica ou ramificada, apresentaram os valores como melhores candidatos para penetração através da BHE.

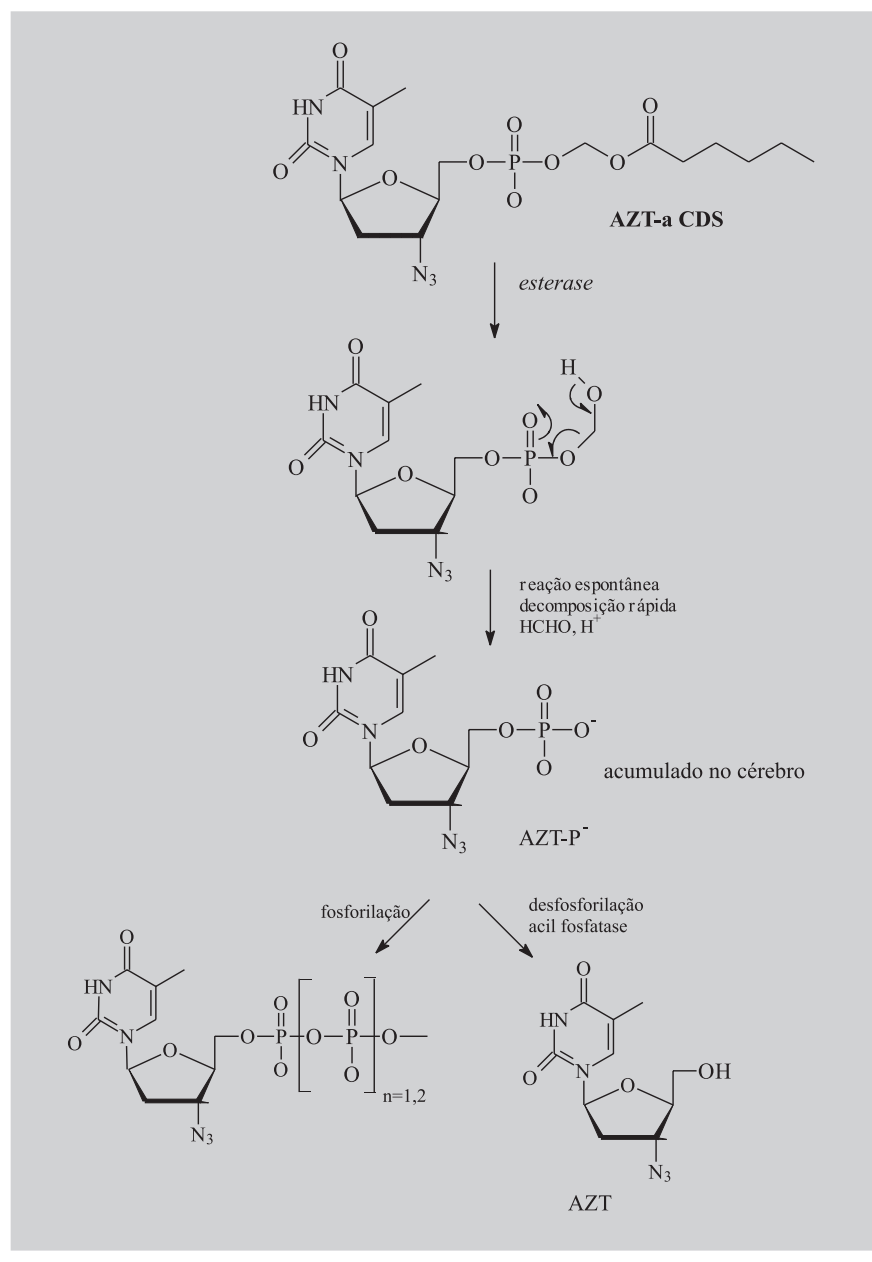

FIGURA 18 - Passos para o acúmulo e liberação de AZT no SNC, utilizando o sistema CDS aniônico (Somogyi et al., 2002).

Outros pró-fármacos seletivos foram preparados como os derivados de $t$-butalona (Reddy et al., 2001), derivados canabinóides (Buchwald et al., 2002), derivados de testosterona (Somogyyi et al., 2002), análogos de TRH (Wu et al., 2002), derivados de estradiol (Tapfer et al., 2004).

\section{Pró-fármacos recíprocos}

Caracterizam-se por seu transportador, diferentemente dos pró-fármacos clássicos, também possuir atividade terapêutica. Dessa forma, pode-se obter pró-fármaco com atividades terapêuticas diferentes ou semelhantes, atuando por mecanismos da ação diferentes ou iguais (Singh, Sharma, 1994). Tal processo é especialmente racional nos casos em que há sinergismo de ação.

Os pró-fármacos recíprocos não são tão recentes, já que vários compostos foram introduzidos na terapêutica antes do reconhecimento do conceito de pró-fármaco. A 
sulfassalazina é um bom exemplo, pois foi utilizada, em 1942, para o tratamento de artrite reumatóide e, atualmente, é utilizada no tratamento de colite ulcerativa. Este prófármaco, após sofrer ação das azo-redutases, libera sulfapiridina e ácido aminossalicílico (5-ASA), ambos farmacologicamente ativos (Figura 21).

Após a descoberta de que o 5-ASA era o responsável pela atividade terapêutica da sulfassalazina, foram desenvolvidos vários outros pró-fármacos derivados do ácido aminossalicílico, incluindo o pró-fármaco recíproco de duas moléculas de 5-ASA, a olsalazina (Figura 22) (Singh, Sharma, 1994; Ettmayer et al., 2004).

Chung, em 1996, sintetizou pró-fármacos recíprocos de primaquina e nitrofural, utilizando espaçantes dipeptídicos, de cisão seletiva pela cruzipaína, com o objetivo de obter derivados potencialmente antichagásicos. $\mathrm{O}$ princípio empregado foi o de que a primaquina, uma vez

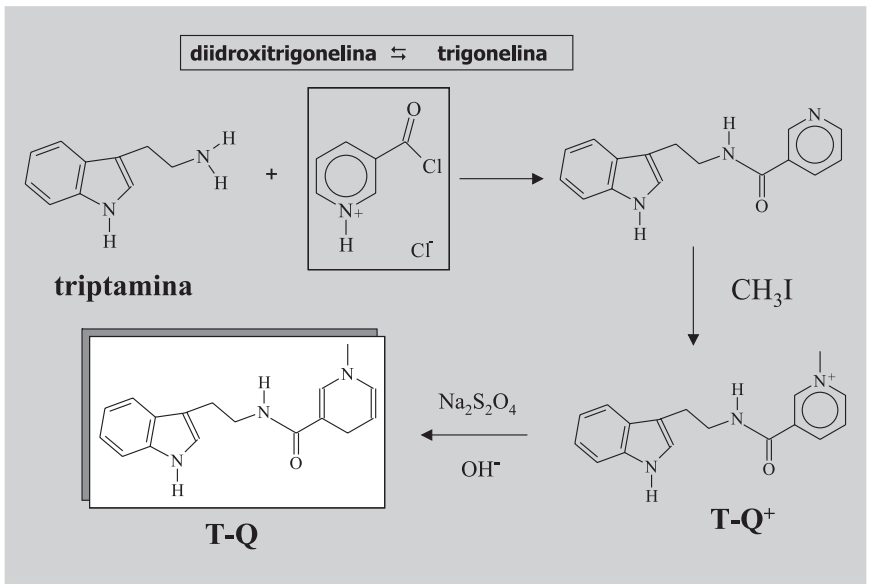

FIGURA 19 - Síntese do pró-fármaco triptamina-CDS (TQ), com alta afinidade pelo tecido cardíaco (Bodor et al., 2001).

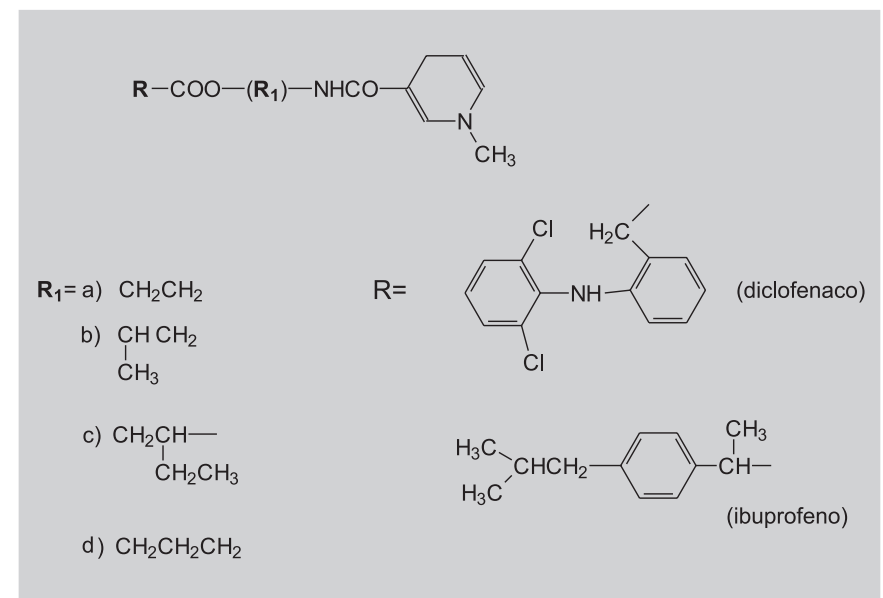

FIGURA 20 - Pró-fármacos antiinflamatórios potenciais para utilização em DA.

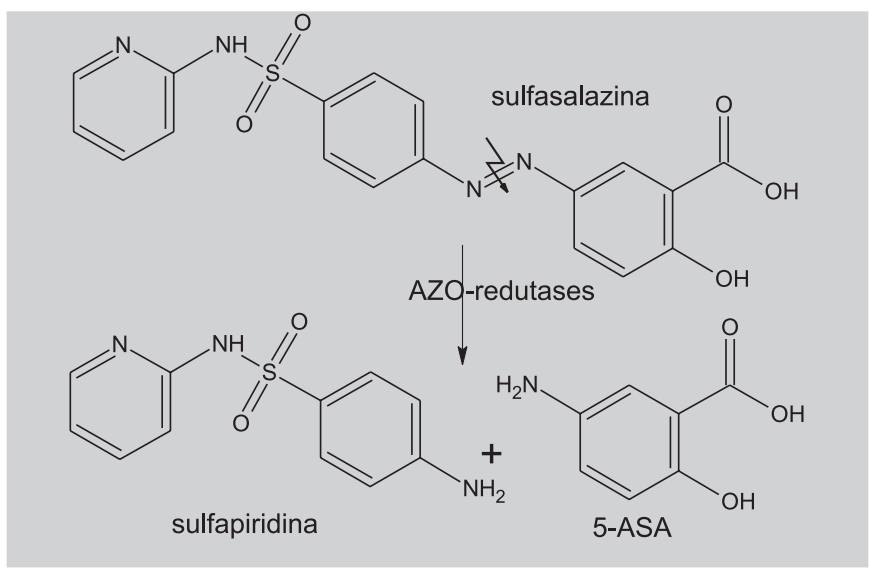

FIGURA 21 - Pró-fármaco recíproco de sulfapiridina e ácido aminossalicílico (5-ASA).

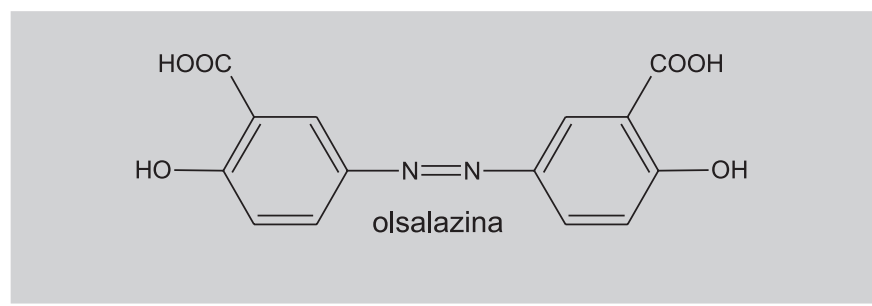

FIGURA 22 - Pró-fármaco recíproco olsalazina.

liberada especificamente pela cruzipaína, aumentaria o estresse oxidativo no parasito, que não poderia ser revertido em razão de que a tripanotiona redutase se encontraria inibida pelo nitrofural. O composto mais ativo, quando ensaiado em cultura de células infectadas com o T.cruzi, foi o derivado com espaçante dipeptídico Lys-Arg (Figura 23). Os intermediários dipeptídicos da primaquina tam-

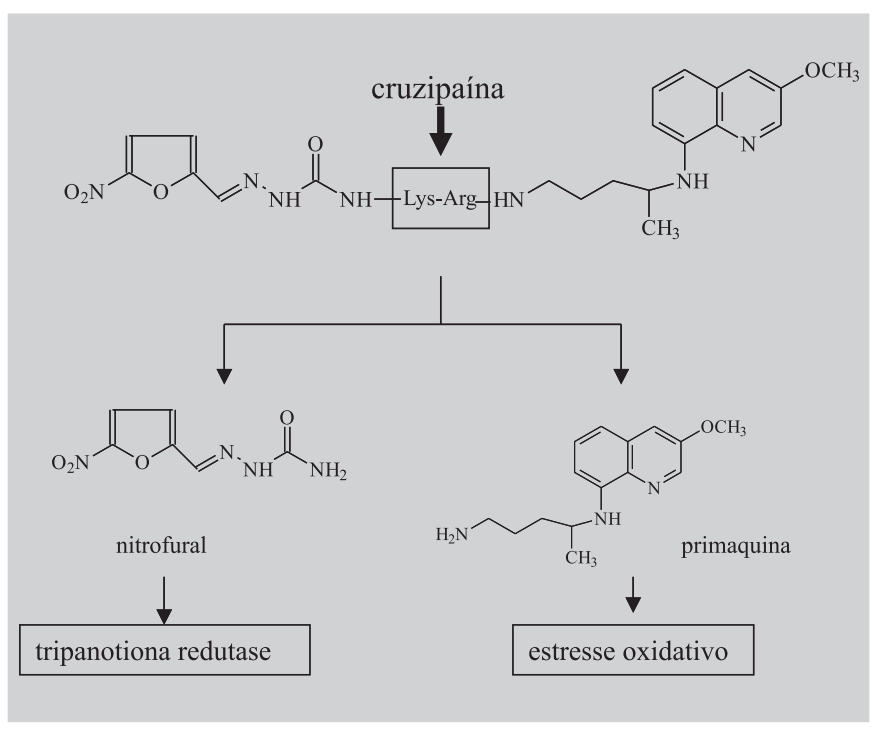

FIGURA 23 - Pró-fármaco recíproco dipeptídico derivado de nitrofural e primaquina, potencialmente antichagásico (Chung, 1996). 
bém se mostraram ativos tanto em amastigotas quanto em tripomastigotas, no mesmo tipo de ensaio biológico in vitro (Chung et al., 1997).

Em 2001, pesquisadores da Novartis desenvolveram pró-fármacos recíprocos inibidores de PDE4 (fosfodiesterase 4) e corticosteróide, ativos no tratamento da asma. Outros pró-fármacos recíprocos antiinflamatórios foram obtidos por Sharma e Khan (2003) e para o tratamento de leucemia, Mann e colaboradores (2003) sintetizaram o butirato de retinoiloximetila, pró-fármaco recíproco do ácido retinóico e ácido butírico, mais ativo que o ácido retinóico isoladamente.

Vlieghe e colaboradores (2002) desenvolveram a $\kappa$ carragenan-3'-azido-3'-desoxitimidina, pró-fármaco recíproco polimérico derivado de zidovudina, possuindo como transportador $\alpha$-carragenina, a qual apresenta atividade anti-HIV intrínseca (Figura 24).

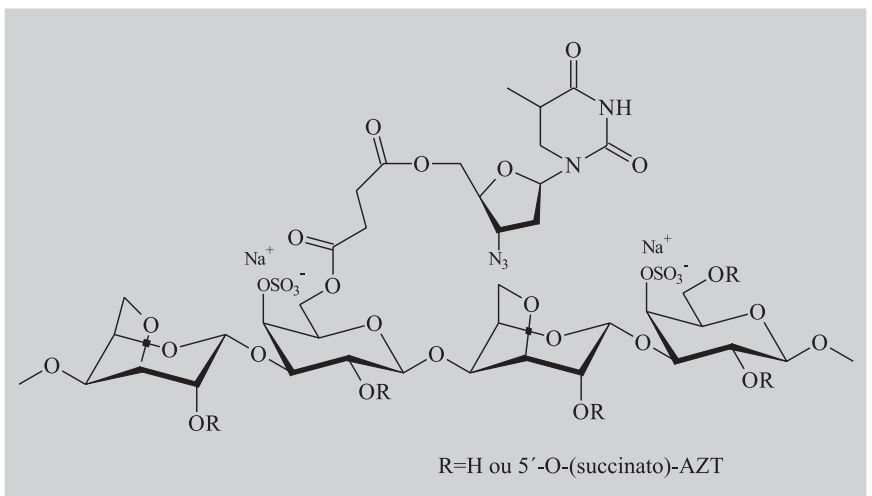

FIGURA 24 - Pró-fármaco polimérico recíproco da zidovudina (Vlieghe et al.., 2002).

\section{Fármacos dirigidos}

A liberação de fármacos direcionados a células via latenciação tem gerado interesse considerável com o objetivo de aumentar a potência e atingir seletividade de ação, diminuindo os efeitos adversos de um fármaco (Han, Amidon, 2000; Hirabayashi et al., 2001). Esta classe consiste em fármacos acoplados a um transportador específico para determinados receptores ou enzimas existentes no sítio de ação específico do fármaco, reduzindo sua ação inespecífica sobre outros órgãos e/ou tecidos.

Os transportadores dos fármacos dirigidos podem ser constituídos de polímeros, que funcionam como suporte para os grupos diretores, ou como, eles próprios, os grupos que dirigem a ação, quando se tratam de macromoléculas específicas, como, por exemplo, anticorpos (Chung, Ferreira, 1999; Ettmayer et al., 2004)

Entretanto, não somente os polímeros são transportadores seletivos. Em 2004, Devy e colaboradores sinte- tizaram pró-fármacos peptídicos de doxorrubicina, planejados racionalmente com base na seletividade da plasmina, baseados nos trabalhos de Chakravarty (1983). Estes prófármacos podem ser ativados localmente em razão dos níveis de plasmina produzidos em alguns tipos de tumores sólidos, através da ação de ativadores de plasminogênio associados ao tumor. Os resultados mostraram seletividade in vitro e in vivo maior que a dos derivados peptídicos em relação ao fármaco de origem.

Com o mesmo objetivo, Trouet e Jolles (1984) prepararam diversos derivados de aminoácidos e peptídios de primaquina com atividade antimalárica e demonstraram que estes derivados eram menos tóxicos que a primaquina. Os peptídios utilizados por estes autores foram os mesmos utilizados no fármaco antineoplásico.

Di ou tri-peptídeos modificados foram planejados como transportadores para pró-fármacos de análogos de purina e pirimidinas com afinidade pelo sistema de transporte de di ou tripeptídeos Pep T1 intestinal (Tomsen et al., 2003).

\section{POLÍMEROS UTILIZADOS COMO TRANSPORTADORES DE FÁRMACOS}

O uso de macromoléculas como transportadores baseia-se na aplicação da latenciação para prolongar a ação e diminuir, conseqüentemente, a toxicidade de um fármaco (Takakura, Hashida, 1995; Nassute, 2002; Ettmayer et al., 2004). Com o início do século 21, prevêse que a interface entre a química de polímeros e as ciências biomédicas dêem origem à "terapêutica com polímeros" (Duncan, 2003).

A quimioterapia para tratamento do câncer é um bom exemplo desta aplicação devido à alta toxicidade dos agentes antitumorais, uma vez que são, na maioria, desprovidos de seletividade (Takakura, Hashida, 1995; Satchi-Fainaro et al., 2003).

Várias biomacromoléculas naturais e sintéticas têm sido empregadas como transportadores de agentes quimioterápicos, partindo-se do conhecimento de que as características anatômicas e fisiológicas dos tecidos neoplásicos são diferentes daquelas dos tecidos normais (Figura 25).

A estrutura anatômica dos vasos em tecidos tumorais é diferente daquela dos normais. Os vasos dos tecidos tumorais apresentam as propriedades de permeabilidade e retenção aumentadas (EPR, Enhanced Permeability and Retention), as quais desempenham papel essencial na distribuição do fármaco no espaço intersticial (O’Connor, Bale, 1984; Matsumara, Maeda, 1986; Jain, 1987; Takakura et al., 1987, 1990; Takakura, Hashida, 1995). São elas: 


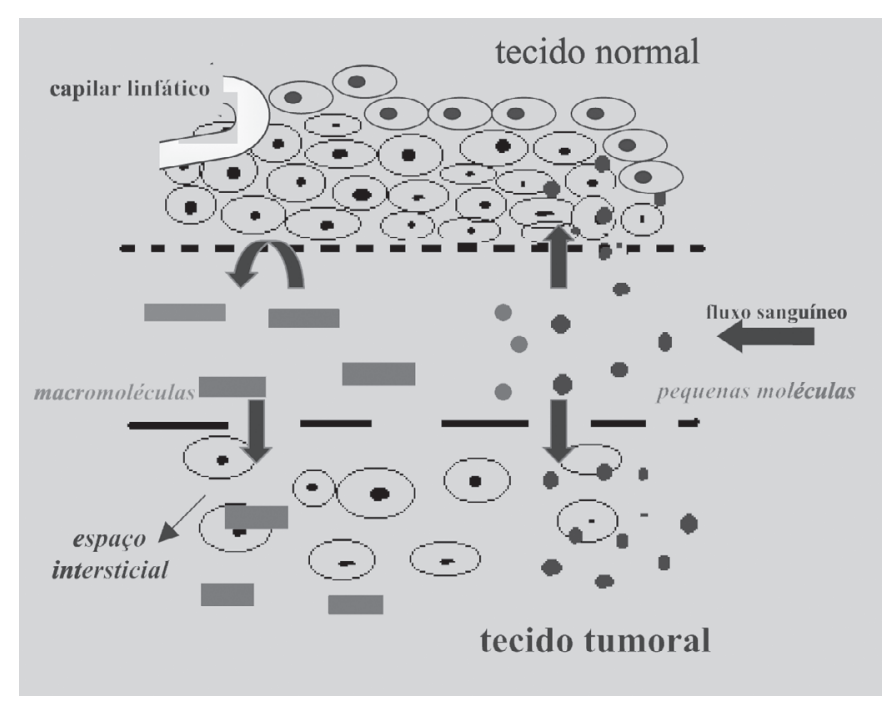

FIGURA 25 - Comportamento de pequenas moléculas e macromoléculas, em tecidos normal e tumoral (modificado de Takakura, Hashida, 1995).

(1) o aumento da permeabilidade microvascular em relação ao vaso normal, o que facilita na penetração de macromoléculas.

(2)a alta pressão intersticial, que pode retardar o extravasamento de macromoléculas, e

(3) a falta de sistema linfático para drenagem, que resulta em acúmulo de macromoléculas no interior dos tecidos tumorais.

O Quadro 1 mostra alguns exemplos dos transportadores mais utilizados na latenciação de fármacos com

QUADRO 1 - Classificação de macromoléculas utilizadas como transportadores não-específicos

\section{Macromoléculas naturais}

- Proteínas (albumina, globulina)

- Polissacarídios (dextrano, quitina, quitosana, inulina)

- Ácidos nucléicos (DNA)

\section{Macromoléculas sintéticas}

- Ácidos poliamínicos (polilisina, ácido poliaspártico, ácido poliglutâmico)

\section{Macromoléculas mistas}

- Copolímero de anidrido estireno de ácido maléico (SMA)

- Copolímero de anidrido éter divinilmaléico (DIVEMA)

- Copolímero de $N$-(2-hidroxipropil)metacrilamida (HPMA)

- Polietilenoglicol(PEG)

- Álcool polivinílico (PVA) propósitos de prolongamento de ação, diminuição de toxicidade, além do uso como suportes para grupos diretores que conferem seletividade.

Yura e colaboradores (1999) prepararam o FK 506-dextrano (Figura 26), pró-fármaco polimérico derivado de tacrólimo (FK 506) e dextrano. O FK 506 é um agente imunossupressor extremamente potente (cerca de 100 vezes mais potente que a ciclosporina), utilizado em terapêutica (EUA, Europa e Japão) na prevenção de rejeições em transplantes de fígado e rins. Entretanto, a utilização deste fármaco na terapêutica requer a administração de injeções freqüentes ou infusões prolongadas, causando graves efeitos adversos, especialmente toxicidade renal. Os resultados obtidos por estes pesquisadores mostraram vantagens na utilização do pró-fármaco em relação ao fármaco matriz (FK 506), pois o mesmo permanece por mais tempo íntegro na circulação sangüínea, levando à redução substancial dos efeitos adversos.

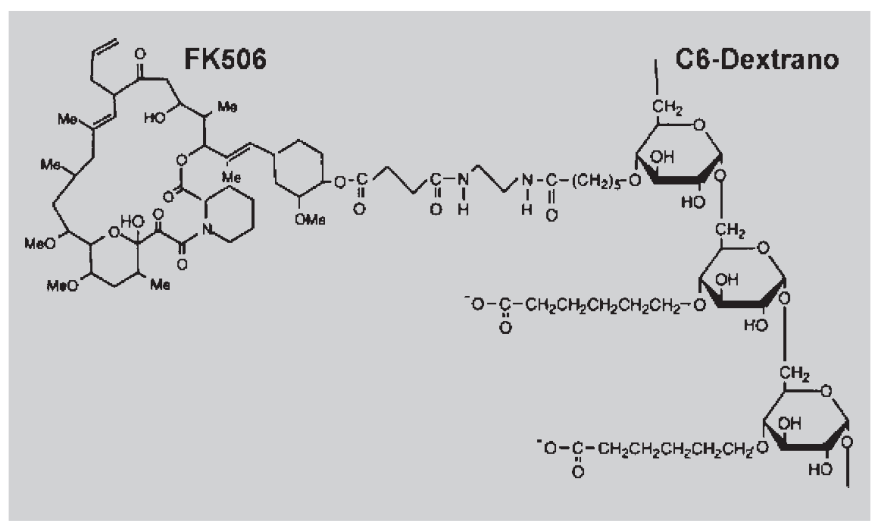

FIGURA 26 - Pró-fármaco polimérico tacrólimo(FK506)dextrano (Yura et al., 1999).

As camptotecinas (CTP), tais como itinotecano (CPT-11) e topotecano, disponíveis clinicamente, representam classe muito promissora de antitumorais, apesar de sua toxicidade. Com o objetivo de alterar o comportamento farmacocinético, aumentando a eficácia e diminuindo a toxicidade desses antineopláiscos, Okuno e colaboradores (2000) sintetizaram o pró-fármaco polimérico denominado de T-0128. Este composto é derivado do análogo da CPT, o T-2513, que, utilizando o carboximetildextrano como transportador e o tripeptídeo Gly-Gly-Gly como agente espaçante (Figura 27), resulta em regressão de tumor sólido, além de se encontrar em concentração tecidual superior à do fármaco matriz.

Outro tipo de transportador que tem despertado interesse na latenciação foi o obtido por Yokoyama e colaboradores $(1990,1991)$. Estes pesquisadores sintetiza- 
ram polímero formador de micela (Figura 28), como transportador de doxorrubicina. Neste, o antineoplásico, por meio do grupo amínico, foi diretamente ligado ao poli(etilenoglicol)-(ácido poliaspártico) através do grupo carboxílico do ácido aspártico da cadeia polimérica, obtendo conjugado de caráter anfifílico.

Silva e colaboradores, em 2001, sintetizaram prófármaco formador de micela de isoniazida (Figura 29), utilizando o mesmo tipo de transportador empregado por Yokoyama e colaboradores $(1990,1991)$. O pró-fármaco mostrou-se ativo em cultura de M. tuberculosis. Outros derivados (Silva, 2001) de rifampicina/isoniazida e pirazinamida mostraram-se, também, mais ativos em cultura que os tuberculostáticos de partida.

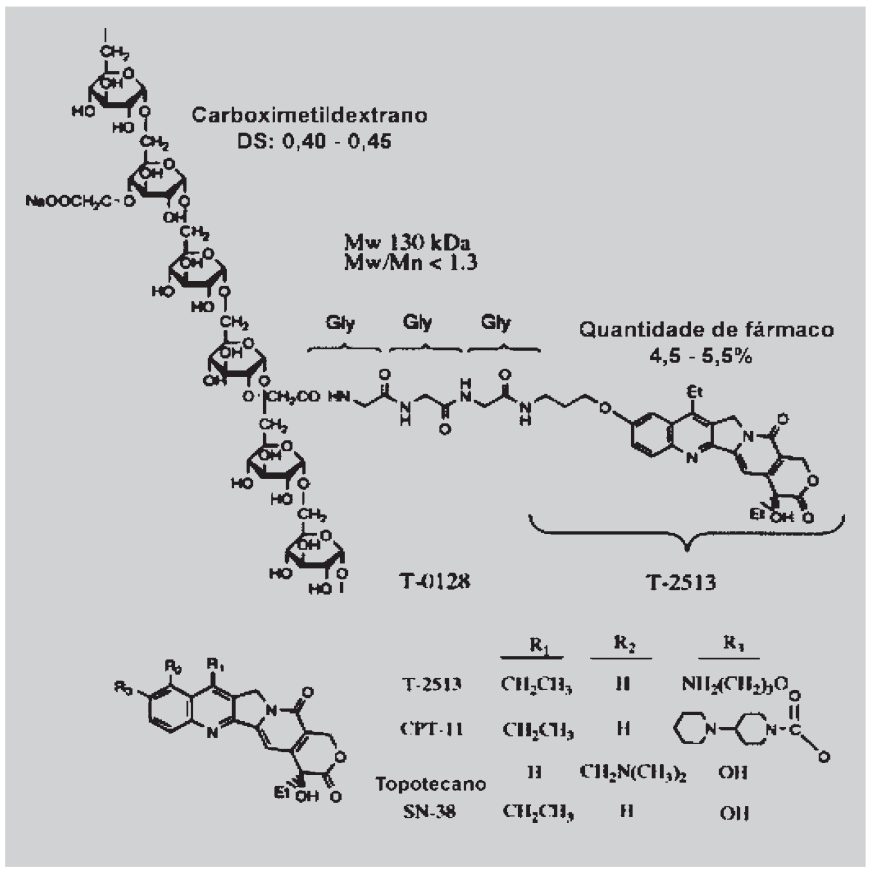

FIGURA 27 - Estruturas químicas do T-0128, T-2513, CPT-11, topotecano e SN-38. DS=grau de substituição de grupos carboximetilados (Okuno et al.., 2000).

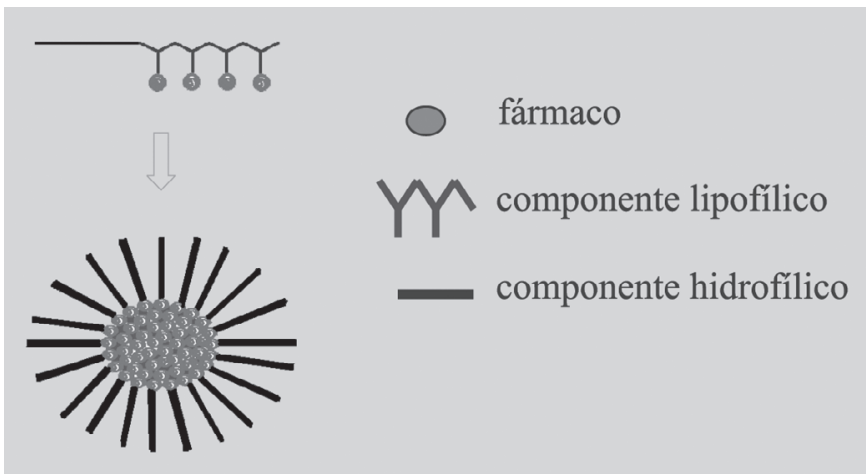

FIGURA 28 - Micela polimérica (Silva, 2001).

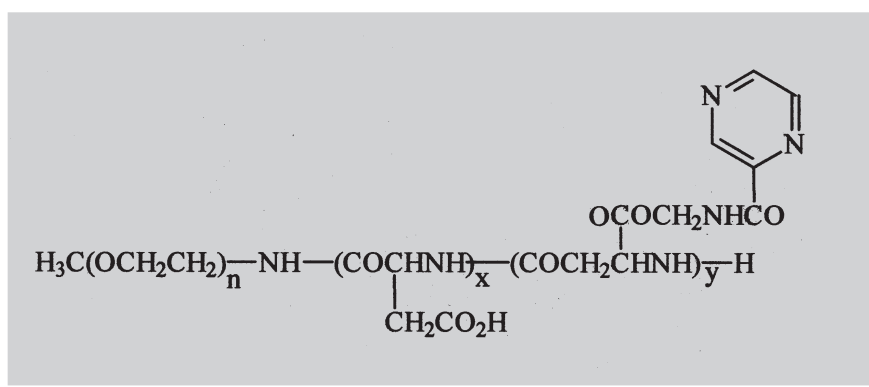

FIGURA 29 - Estrutura provável do pró-fármaco formador de micela derivado de isoniazida (Silva et al., 2001).

Nishikawa e colaboradores (1993) utilizaram carboximetil e succinildextranos como transportadores ligados a grupos diretores com o objetivo de obter liberação hepática específica. Aplicado à mitomicina, esse processo mostrou-se promissor no planejamento de fármacos dirigidos potencialmente antineoplásicos. Com base nessa abordagem e com o objetivo de obter fármacos dirigidos a receptores manosídicos de macrófagos infectados com Leishmania, Carvalho e colaboradores (2003) sintetizaram carboximetildextranotiomanopirosídeo-pirimetamina (CMD-P) e succinildextrano-tiomanopiranosídeo-pirimetamina (SD-P) (Figura 30). Ensaiados em cultura de macrófagos infectados, o mais ativo foi o CMD-P, que provocou $46,4 \%$ de inibição, na concentração de $200 \mu \mathrm{g} / \mathrm{mL}$.

Empregando-se o mesmo tipo de planejamento, Scarlato et al. (1999) sintetizaram fármacos dirigidos de

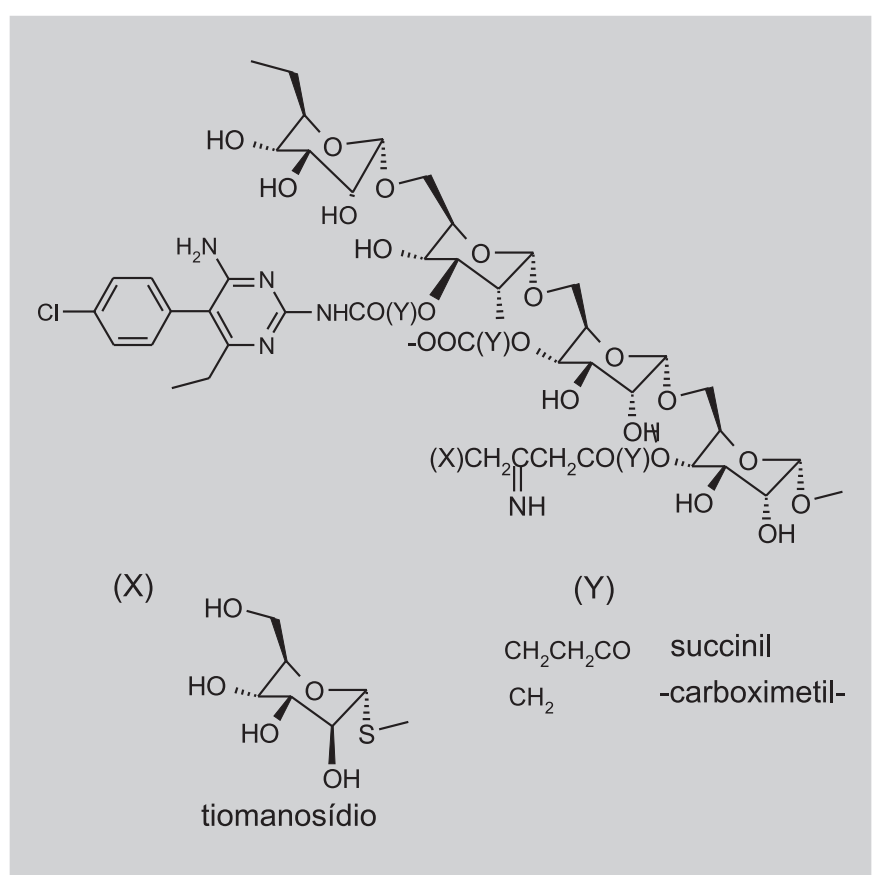

FIGURA 30 - Estrutura resumida dos fármacos dirigidos de pirimetamina, potencialmente leishmanicidas (Carvalho et al., 2003). 
primaquina de liberação hepática específica (Figura 31). Ensaiado em camundongos infectados com P. berghei, o succinildextrano-galactopiranosídeo-primaquina mostrou-se promissor, com maior atividade que o protótipo antimalárico.

Além de promover liberação lenta do fármaco matriz, os pró-fármacos poliméricos podem diminuir a toxicidade do fármaco, aumentando sua seletividade. Com tal objetivo, o pró-fármaco polimérico PK-2 (HMPAdoxorrubicina-galactosamina) (Figura 32) foi planejado contendo um grupo diretor para o fígado e encontra-se em fase clínica II, para o tratamento de carcinoma hepatocelular e doenças secundárias desse órgão (Ferry et al., 1999; Duncan et al., 2001).

Outro transportador seletivo foi desenvolvido por Erion e colaboradores (2004), que sintetizaram série de pró-fármacos fosfatos e fosfonatos, denominados prófármacos HelpDirect ${ }^{\circledR}$, hepatoespecíficos, resultando na liberação do fármaco no fígado, após cisão oxidativa catalisada pelas enzimas do sistema CYP-450 (Figura 33). Estes compostos não promoveram a formação de subprodutos tóxicos no fígado de animais tratados, sugerindo que esta é uma boa estratégia para terapias contra doenças hepáticas como a hepatite $\mathrm{C}, \mathrm{B}$ e carcinoma hepatocelular.

O pró-fármaco (1) difunde-se para o interior dos hepatócitos e sofre oxidação pela ação do CYP- $3^{\mathrm{a}}$, produzindo o derivado C4-hidroxilado (2), cujo anel é rápida e irreversivelmente aberto, levando à formação de um intermediário monoácido (3). Este ácido gera o fosfato ou

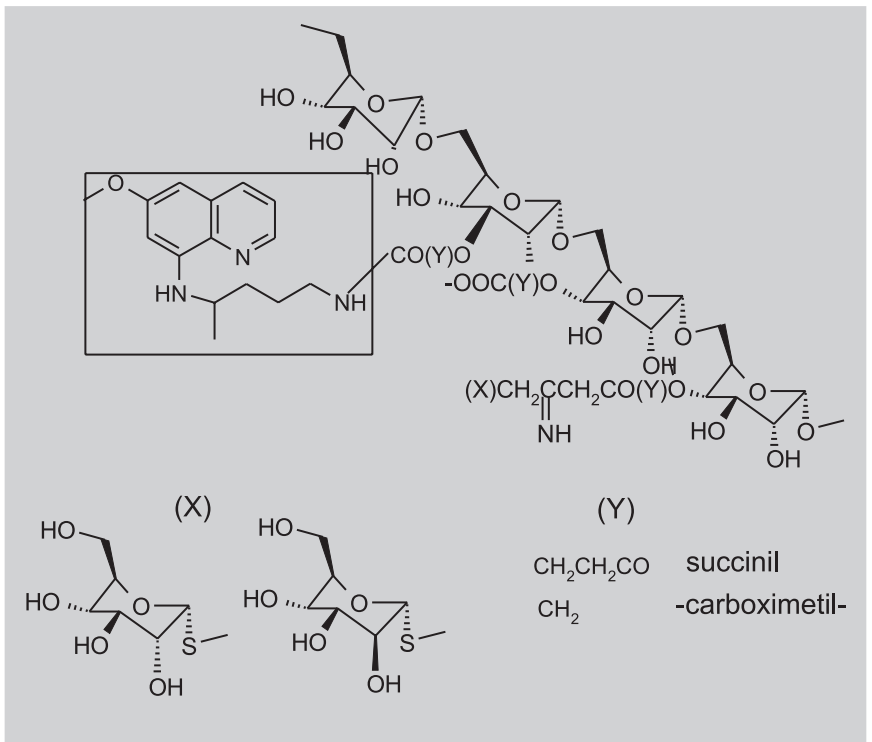

FIGURA 31 - Estrutura resumida dos fármacos dirigidos de primaquina, potencialmente antimaláricos (Scarlato et al., 1999).

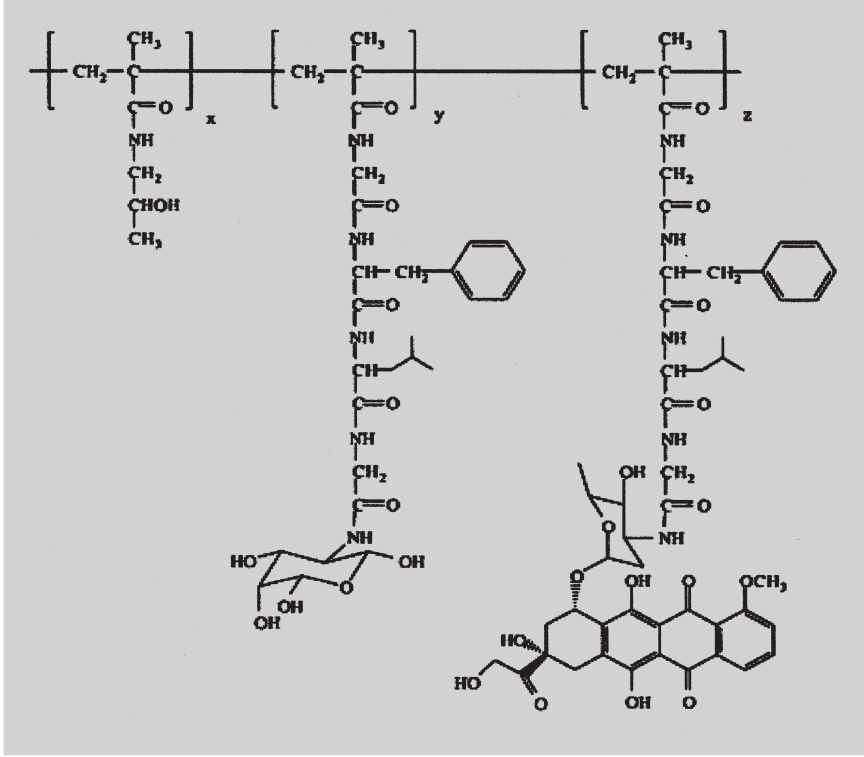

FIGURA 32 - Pró-fármaco polimérico PK-2 (HMPAdoxorrubicina-galactosamina, hepato-específico) (Ferry et al., 1999; Duncan et al., 2001).

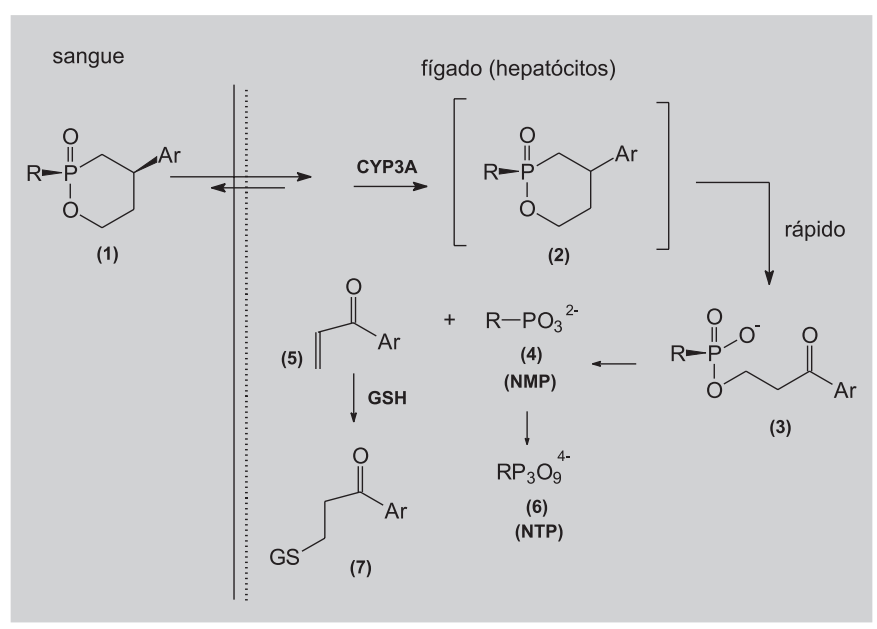

FIGURA 33 - Mecanismo de cisão dos pró-fármacos HelpDirect ${ }^{\mathbb{R}}$.

fosfonato correspondente (4) e uma cetona arilvinílica (5), que sofre uma $\beta$-eliminação ou possível ação de hidrólise enzimática. $\mathrm{O}$ composto 4 é convertido biologicamente em análogo nucleosideo trifosfato (NTP, 6) por ação de nucleotídeos quinases intracelulares, quando RPO3- for um análogo de nucleosídeo monofosfato (NMP) e por PRPP sintase, quando o análogo de NMP for a PMEA (9[2-fosfonilmetoxietil]adenina ou adefovir).

A figura 34 mostra as estruturas químicas dos prófármacos HelpDirect ${ }^{\mathbb{R}} \mathrm{MBO} 07133$, derivado da citarabina (araC) 5'-monofosfato e MB06866, derivado do análogo de nucleotideo adefovir (PMEA) (Erion et al., 2004) 


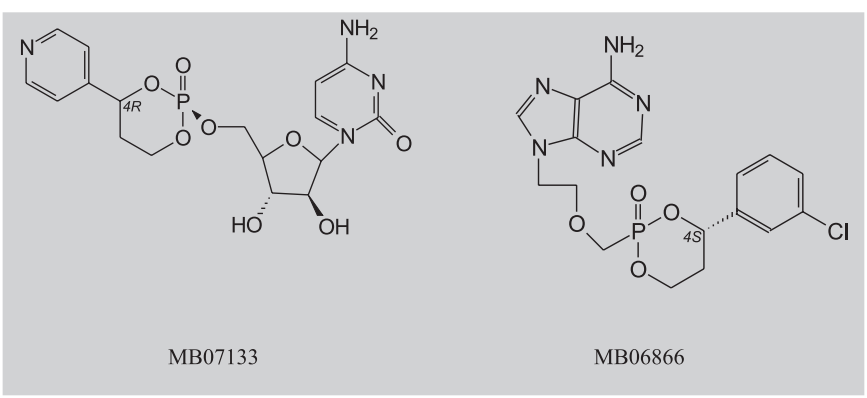

FIGURA 34 - Estruturas químicas dos pró-fármacos HelpDirect ${ }^{\mathbb{Q}}$ MBO07133, derivado da citarabina (araC) 5' monofosfato e MB06866, derivado do análogo de nucleotídeo adefovir (PMEA) (Erion et al., 2004).

\section{NOVAS ESTRATÉGIAS PARA A LATENCIAÇÃO UTILIZANDO TRANSPORTADORES POLIMÉRICOS}

Com base em estudos envolvendo a distribuição do fármaco no espaço vascular, a sua penetração através da parede microvascular, movimento através do espaço intersticial e interação com a superfície celular, explorando o efeito EPR, novas estratégias foram propostas para o desenvolvimento de polímeros terapêuticos de segunda geração.

No sistema de liberação lisossomotrópico, o fármaco é liberado após endocitose celular e ação de enzimas lisossômicas. Na intracitoplasmática, a liberação ocorre no compartimento endossômico, para promover a liberação no citosol. A velocidade lenta para internalização destes prófármacos pode limitar a utilização destes sistemas lisossomotrópicos ou endossomotrópicos. Assim sendo, foram desenvolvidas estratégias para liberação mais rápida, extracelularmente, como (Duncan et al., 2001) (Figura 35):

1. pró-fármacos conjugados poliméricos ativos em membrana, o qual encontra-se ainda em fase inicial de pesquisa, e os

2. sistemas de duas etapas: sistemas PDEPT (PolymerDirected Enzyme Prodrug Therapy) e PELT (Polymer-enzyme Liposome Therapy).

O sistema PDEPT utiliza combinação de fármacopolímero e polímero-enzima para gerar o agente citotóxico rapidamente extracelularmente, isto é, no interstício do tumor. O primeiro sistema PDEPT descrito utilizou o sistema HPMA-co-MA-GFLG-doxorrubicina (PK1), que se encontra, atualmente, em fase de pesquisa clínica II (Satchi-Fainaro et al., 2003) (Figura 36) e a figura 37 mostra o mecanismo de liberação do agente citotóxico.

Recentemente, Robinson e colaboradores (2004) desenvolveram outro sistema, que denominaram LEAPT (Lectin-Directed Enzyme-Activated Prodrug Therapy). Trata-se de sistema de liberação bipartite, que explora o

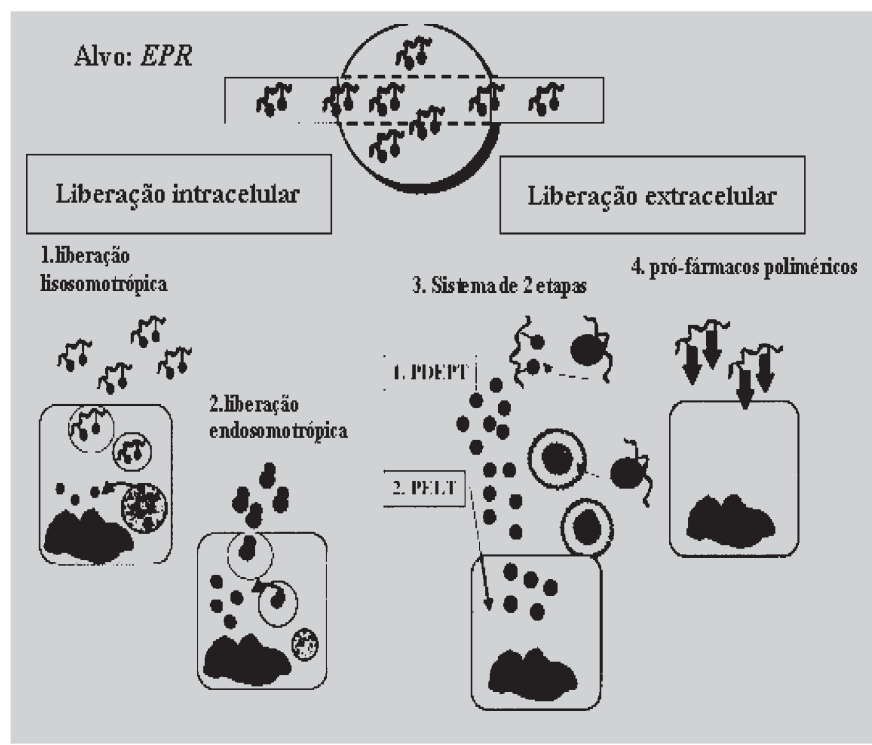

FIGURA 35 - Representação esquemática dos sistemas PDEPT e PELT (Ducan et al., 2001).

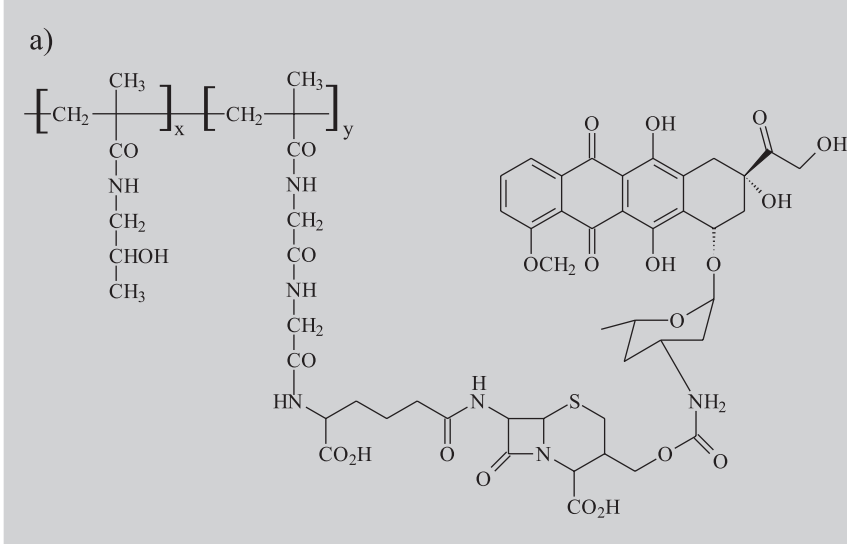

b)

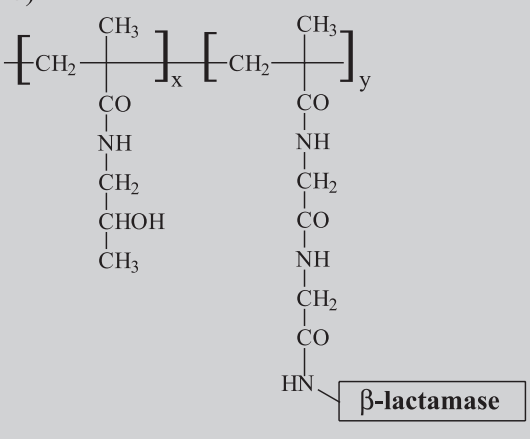

FIGURA 36 - Estrutura química de (a) HPMA-co-MAGG-C-Dox e (b) HPMA-co-MA-GG- $\beta$-L.

sistema endógeno de ligações de carboidrato à lecitina, para internalizar o conjugado de enzima-glicosilada (ex. raminosidase glicosilada), por endocitose, em células específicas e pré-determinadas. Em seguida, é administrado o pró-fármaco (conjugado substrato-fármaco), que é ativa- 


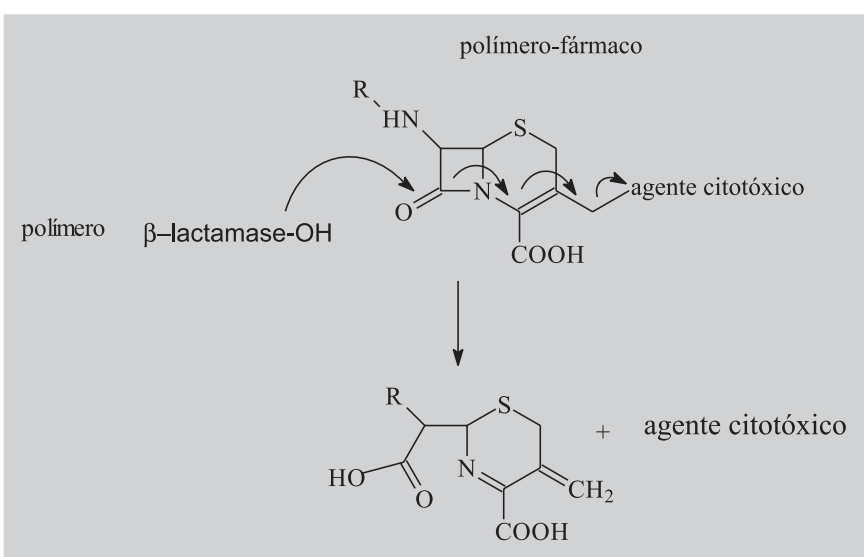

FIGURA 37 - Mecanismo de liberação do agente citotóxico do conjugado HPMA-co-MA-GFLG-doxorrubicina (Satchi-Fainaro et al., 2003).

do pela enzima pré-liberada no sítio de ação desejado. Este sistema mostrou-se possível para utilização em hepatócitos como tecido alvo.

Os pró-fármacos poliméricos também podem ser utilizados em conjunto com a farmacotécnica para melhoria da atividade. A Figura 38 mostra a conjugação de fármacos a ácido poli-(dl-lático-co-glicólico) (PLGA) para utilização em microsferas de liberação controlada (Oh et al., 1999).

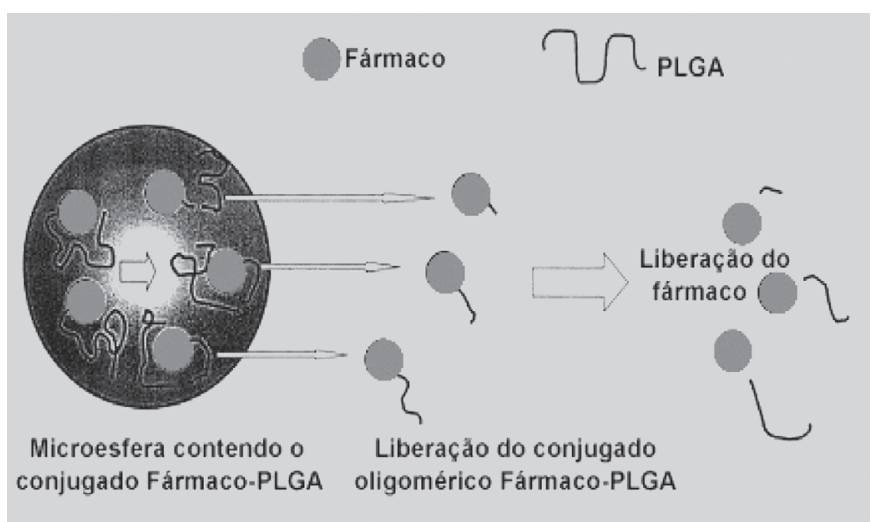

FIGURA 38 - Representação esquemática do sistema conjugado fármaco-PLGA(Oh et al., 1999).

\section{SISTEMAS DE ALTA SELETIVIDADE - Terapia enzima pró-fármaco (Enzyme prodrug therapy)}

Com o avanço das técnicas de clonagem e de expressão controlada de genes em células de mamíferos, elucidou-se, recentemente, a estrutura tridimensional de enzimas e transportadores de membrana, tornando possível o planejamento racional de fármacos dirigidos (Han, Amidon, 2000).

Fazem parte dessa classe de formas latentes de alta seletividade de ação os sistemas: ADEPT - Antibody-
Directed Enzyme Prodrug Therapy e GDEPT/VDEPT

- Gene-Directed Enzyme Prodrug Therapy/VirusDirected Enzyme Prodrug Therapy.

\section{ADEPT - Terapia dirigida por anticorpo-enzima-pró- fármaco}

A eficácia da quimioterapia para o tratamento do câncer é limitada pela ocorrência dos efeitos colaterais, devido à falta de seletividade dos antineoplásicos de uso corrente em relação às células normais e ao aparecimento de células tumorais resistentes aos fármacos (Houba et al., 1996; Xu, McLeod, 2001).

O sistema ADEPT utiliza enzima não existente no organismo, acoplada a um anticorpo monoclonal, para ativar o pró-fármaco, aumentando, significativamente, a seletividade dos agentes anticancerígenos (Ettmayer et al., 2004) (Figura 39).

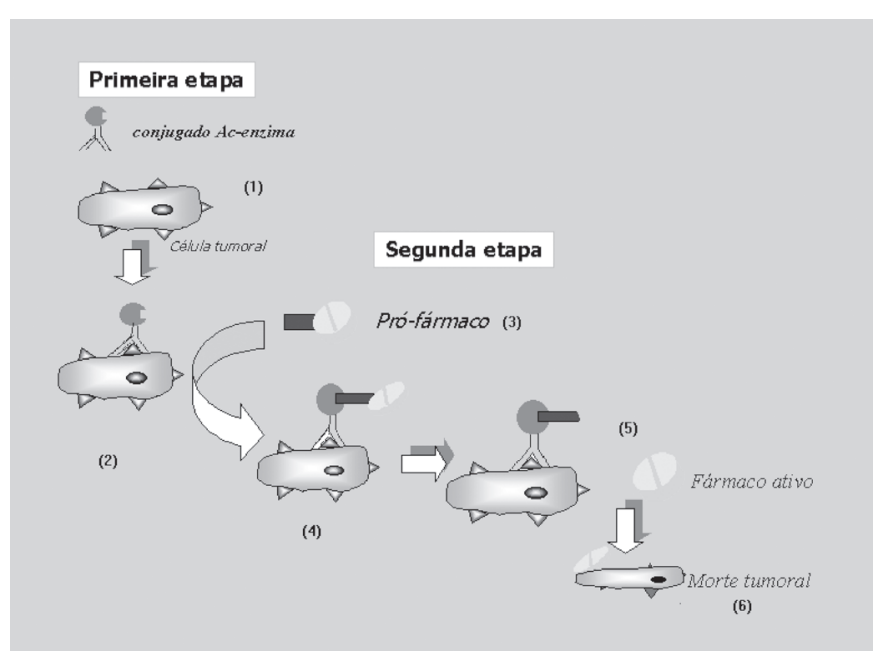

FIGURA 39 - Representação esquemática de ADEPT. O anticorpo reconhece a superfície da célula tumoral (1) e (2); o pró-fármaco é administrado e é direcionado para ser clivado pela enzima ligada ao anticorpo (3) e (4) e liberar o fármaco (5) e promover citotoxicidade (6).

Primeiramente, administra-se o conjugado anticorpo monoclonal acoplado à enzima (1); o anticorpo reconhece a superfície de uma determinada célula neoplásica (2). Administra-se, então, o pró-fármaco (3), que, quando se aproxima do complexo monoclonal-enzima ligado à célula neoplásica, é clivado (4), liberando o fármaco ativo (5), o qual promoverá ação (6) contra a célula tumoral (Houba et al., 1996; Duvaz, Springer, 1997; Han, Amidon, 2000; Wang et al., 2001; Ettmayer et al., 2004).

Várias classes de tumores humanos têm se mostrado sensíveis à utilização de diferentes combinações de anticorpo, enzima e pró-fármaco no sistema $\operatorname{ADEPT~}(\mathrm{Xu}$, 
McLeod, 2001; Han, Amidon, 2000).

Experimentos clínicos recentes indicam que o ADEPT pode tornar-se uma forma de tratamento eficaz contra tumores sólidos, desde que se conheçam os anticorpos específicos. (Han, Amidon, 2000). Os anticorpos que se ligam aos antígenos de superfície da célula tumoral, por exemplo, são os componentes chave do sistema ADEPT, uma vez que conferem seletividade ao prófármaco, posteriormente cindido pela enzima do conjugado.

Os pró-fármacos devem ter lipossolubilidade ótima e, por essa razão, ao invés de se utilizar anticorpos íntegros, podem-se utilizar, com eficiência, somente os fragmentos Fab e scFv (Figura 40) (Duvaz, Springer, 1997; Senter, Springer, 2001).

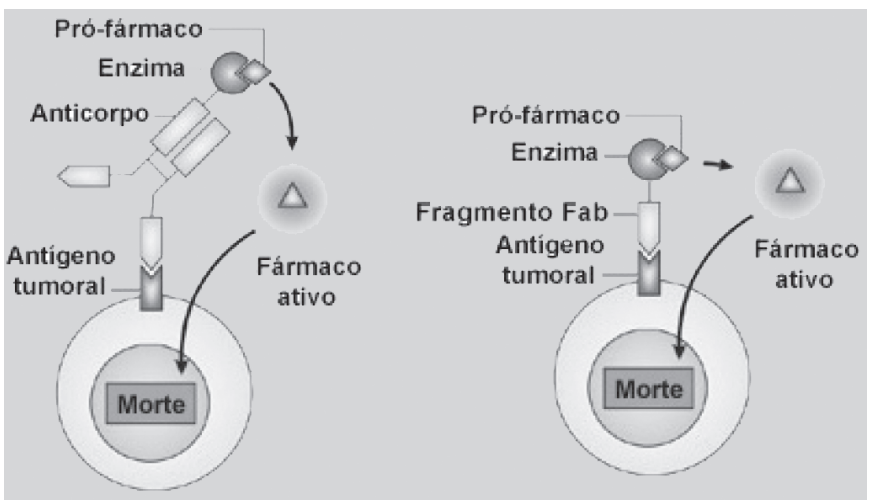

FIGURA 40 - Representação esquemática de ADEPT com um anticorpo e com o fragmento Fab.

Os pró-fármacos desenvolvidos para o sistema ADEPT devem ser menos citotóxicos que seus fármacos ativos correspondentes, requerendo, também, grande conhecimento da relação entre a estrutura e atividade biológica (Duvaz, Springer, 1997).

Tanto no sistema ADEPT quanto no GDEPT, prefere-se a utilização de enzimas que não sejam de mamíferos ou não-humanas, que possam catalisar substratos geralmente não ativados em humanos. Portanto, as enzimas de origem bacteriana, nas quais se pode controlar a imunogenicidade, são vantajosas, uma vez que conferem maior especificidade à liberação do fármaco da forma latenciada, administrado na segunda etapa do processo (Han, Amidon, 2000).

As enzimas do sistema ADEPT podem ser divididas em três classes, segundo sua origem: (Duvaz, Springer, 1997; Senter, Springer, 2001)

Enzimas de origem mamífera: Fosfatase alcalina (AP); $\alpha$-galactosidase $(\alpha-\mathrm{g})$.

Enzimas de origem não-mamífera com homologia mamifera: carboxipeptidase $\mathrm{A} ; \beta$-glicuronidase $(\beta$-g) de $E$. coli; nitrorredutase (NR) de E. coli.
Enzimas de origem não-mamífera sem homologia mamifera: $\beta$-lactamase ( $\beta$-L); carboxipeptidase $\mathrm{G} 2$ (CPG2); citosina deaminase (CD); benzilpenicilina amidase (PGA); fenoximetilpenicilina amidase (PVA).

Várias combinações de enzimas e pró-fármacos (Quadro 2) já foram propostas para os sistemas ADEPT e GDEPT, a ser descrito posteriormente, observando-se que há combinações mais adequadas para um sistema do que para outro, uma vez que a ativação do pró-fármaco no sistema ADEPT é feita no meio extracelular, enquanto que no GDEPT esta ocorre no meio intracelular (Han, Amidon, 2000).

O sistema ADEPT possui as seguintes vantagens e desvantagens (Duvaz, Springer, 1997).

Vantagens:

- Possibilidade de uso clínico;

- Aumento de seletividade para células malignas;

- Liberação do fármaco ativo, que tem baixa massa molecular, penetrando facilmente na célula tumoral;

- A concentração do fármaco na célula tumoral é bem maior quando o mesmo é administrado na forma de pró-fármaco;

- Não há necessidade de internalização do complexo anticorpo enzima;

- Amplificação do efeito, uma vez que uma enzima pode atuar em diversos pró-fármacos.

\section{Desvantagens:}

- Imunogenicidade do complexo anticorpo-enzima. Tal problema pode ser resolvido usando-se anticorpo com enzima de mamíferos;

- Potencial para matar célula normal devido à liberação do fármaco pela célula tumoral morta. Esse inconveniente pode ser solucionado pelo uso de fármacos com meia-vida curta.

\section{Exemplos de pró-fármacos utilizados para o ADEPT}

O ZD2767 (Figura 41) é um pró-fármaco que se encontra na fase pré-clínica de desenvolvimento. Este se mostrou, pelo sistema ADEPT, capaz de regredir tumores cólon-retais (Duvaz, Springer, 1997; Francis et al., 2002).

Wei e Pei, em 2000, sintetizaram os derivados 5'dipeptidil da fluordesoxiuridina (FdU) biologicamente inativos, mas passíveis de ativação pela peptildesformilase (PDF), a qual remove o grupo formil $N$-terminal do dipeptídeo, para liberar o fármaco ativo FdU. Esta enzima é exclusiva de bactérias e ausente em células de mamíferos, podendo gerar potentes agentes antibacterianos.

Em 2001, Wang e colaboradores sintetizaram um pró-fármaco constituído por uma cefalosporina e um análogo do composto CC-1065 (Figura 42), para ser liberado 
QUADRO 2 - Enzimas, pró-fármacos e respectivos fármacos, que têm sido propostos na terapia do câncer

\begin{tabular}{|c|c|c|}
\hline$\overline{\text { ENZIMA }}$ & PRÓ-FÁRMACO & FÁRMACO \\
\hline DT diaforase & $\begin{array}{l}\text { 5-(aziridin-1-il)-2,4-nitrobenzamida } \\
\text { (CB 1954) }\end{array}$ & $\begin{array}{l}\text { 5-(aziridin-1-il)-4-hidroxil- } \\
\text { amino-2-nitrobenzamida }\end{array}$ \\
\hline Plasmina & $\begin{array}{l}\text { mostarda de peptidil- } p \text { - } \\
\text { feniletilenoamina }\end{array}$ & $\begin{array}{l}\text { mostarda de } \\
\text { feniletilenoamina }\end{array}$ \\
\hline Carboxipeptidase $\mathbf{G} 2$ & $\begin{array}{l}\text { glutamatos da mostarda } \\
\text { de ácido benzóico }\end{array}$ & $\begin{array}{l}\text { mostarda de ácido } \\
\text { benzóico (várias) }\end{array}$ \\
\hline Timidina quinase (viral) & $\begin{array}{l}\text { ganciclovir-metoxipurina } \\
\text { arabinonucleosídeo (araM) }\end{array}$ & $\begin{array}{l}\text { trifosfato de ganciclovir trifosfato de } \\
\text { adenina arabinonucleosídeo (araATP) }\end{array}$ \\
\hline Citosina desaminase & 5-fluorcitosina & 5-fluoruracila \\
\hline Glicose oxidase & glicose & peróxido de hidrogênio \\
\hline Xantina oxidase & hipoxantina & superóxido, peróxido de hidrogênio \\
\hline Carboxipeptidase $\mathbf{A}$ & metotrexato-alanina & metotrexato \\
\hline$\alpha$-Galactosidase & $\begin{array}{l}N \text {-[4-( } \alpha \text {-d-galactopiranosil }) \\
\text { benziloxicarbonil]- } \\
\text { daunorrubicina }\end{array}$ & daunorrubicina \\
\hline$\beta$-Glicosidase & amidalina & cianeto \\
\hline Azorredutase & mostardas de azobenzeno & $\begin{array}{l}\text { mostardas de feniletilenoamina } \\
\text { (várias) }\end{array}$ \\
\hline$\gamma$-Glutamil transferase & $\begin{array}{r}\gamma \text {-glutamil-mostarda de } \\
p \text {-feniletilenodiamina }\end{array}$ & mostarda de feniletilenoamina \\
\hline$\beta$-Glicuronidase & $\begin{array}{l}\text { mostarda fenólica-glucoronideo } \\
\text { e pirrubicina-glicuronídeo }\end{array}$ & $\begin{array}{l}\text { mostarda fenólica } \\
\text { e pirrubicina }\end{array}$ \\
\hline$\beta$-Lactamase & $\begin{array}{l}\text { vinca-cefalosporina } \\
\text { mostarda de feniletilenamina - } \\
\text { cefalosporina } \\
\text { mostrada nitrogenada-cefalosporina }\end{array}$ & $\begin{array}{l}\text { 4-desacetilvimblastina-3- } \\
\text { carboxiidrazina } \\
\text { mostarda de feniletilenamina } \\
\text { mostradas nitrogenadas (várias) }\end{array}$ \\
\hline Fosfatase alcalina & $\begin{array}{l}\text { fosfato de mostarda fenólica } \\
\text { fosfato de doxorrubicina } \\
\text { fosfato de mitomicina } \\
\text { fosfato de etoposídeo }\end{array}$ & $\begin{array}{l}\text { mostarda fenólica } \\
\text { doxorrubicina } \\
\text { mitomicina alcoólica } \\
\text { etoposídeo }\end{array}$ \\
\hline Penicilina amidase & $\begin{array}{l}\text { palitoxina-4-hidroxifenil-acetamida } \\
\text { doxorrubicina-fenoxiacetamida } \\
\text { melfalano-fenoxiacetamida }\end{array}$ & $\begin{array}{l}\text { palitoxina } \\
\text { doxorrubicina } \\
\text { melfalano }\end{array}$ \\
\hline Citocromo P-450 & $\begin{array}{l}\text { ciclofosfamida } \\
\text { ifosfamida }\end{array}$ & $\begin{array}{l}\text { mostarda fosfamídica } \\
(+ \text { acroleína })\end{array}$ \\
\hline Nitrorredudutase & $\begin{array}{l}\text { CB } 1954 \\
\text { derivados de 4-nitrobenzilcarbonila }\end{array}$ & $\begin{array}{l}\text { 5-(aziridin-1-il)-4-hidroxil- } \\
\text { amino-2-nitrobenzamida } \\
\text { dactinomicina, mitomicina C }\end{array}$ \\
\hline
\end{tabular}

Fonte: Han, Amidon, 2000.

por $\beta$-lactamase ligada a anticorpo no sistema ADEPT. Por meio de testes in vitro, o pró-fármaco mostrou-se 10 vezes menos tóxico que o fármaco livre e eficaz in vitro contra células tumorais (leucemia U937).

Os pró-fármacos planejados por esta estratégia com alvo em câncer de próstata encontram-se em fase de desenvolvimento pré-clinico (Wang et al., 2004).

Com base nestes estudos, estes mesmos pesquisadores sintetizaram conjugados pró-fármacos análogos do composto CC-1065 para utilização em sistema ADEPT, sensível à $\beta$-glicuronidase. O mecanismo de conversão proposto para estes derivados encontra-se na Figura 43. 


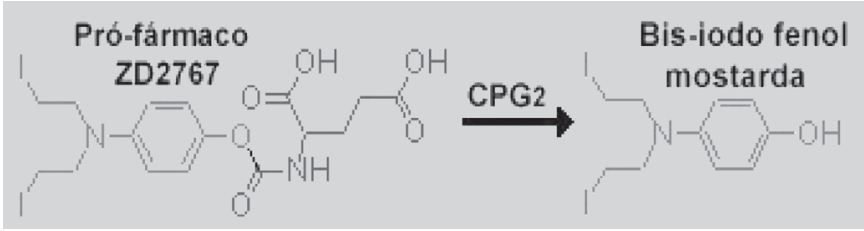

FIGURA 41 - Pró-fármaco ZD2767 (Francis et al., 2002).

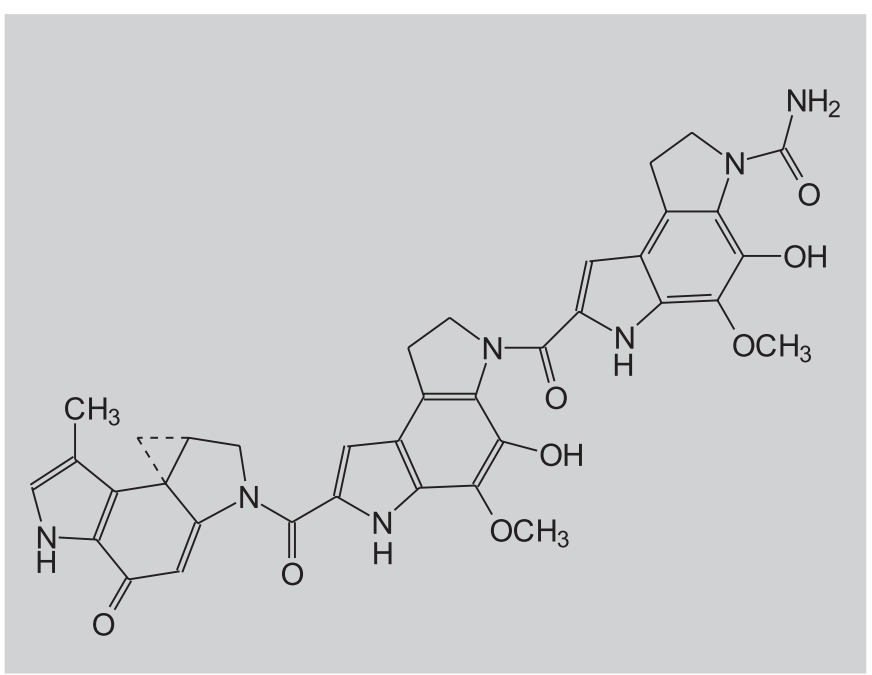

FIGURA 42 - Estrutura do composto (+) CC-1065.

Vários outros antitumorais e sistemas enzimáticos estão sendo estudados com base nesta estratégia (Chen et al., 2003; Heinis et al., 2004), como os derivados de paclitaxel (Bouvier et al., 2003, 2004), antraciclinas (HariKrishna et al., 2003) e dinitrobenzamidas (Johansson et al., 2003).

\section{GDEPT/VDEPT - Terapia dirigida por gene/vírus- enzima-pró-fármaco}

Este processo utiliza genes que codificam enzimas ativadoras de pró-fármacos, os quais podem ser transportados por lipossomas, lipídios catiônicos ou vírus (retrovírus ou adenovírus), atingindo células neoplásicas e normais (Figura 44). A expressão de tais genes pode ser feita ligando-se os mesmos nas unidades de transcrição específicas do tumor. Esta abordagem tem mostrado resultados promissores in vitro e também em pacientes (Grove et al., 1999; Han, Amidon, 2000; Hull, Chester, 2002; Palmer et al., 2004).

Esse tipo de forma de transporte altamente específico tem sido muito estudado para se obter especificidade com antineoplásicos (Kerr et al., 1999; Green et al., 2004).

Hay e colaboradores, em 1999, sintetizaram um prófármaco derivado do carbamato de 2-nitroimidazol-5ilmetila, o qual, na presença de nitrorredutase (NR) (Figura 45), mostrou citotoxicidade 10 a 24 vezes maior contra carcinoma ovariano humano (SKOV3).

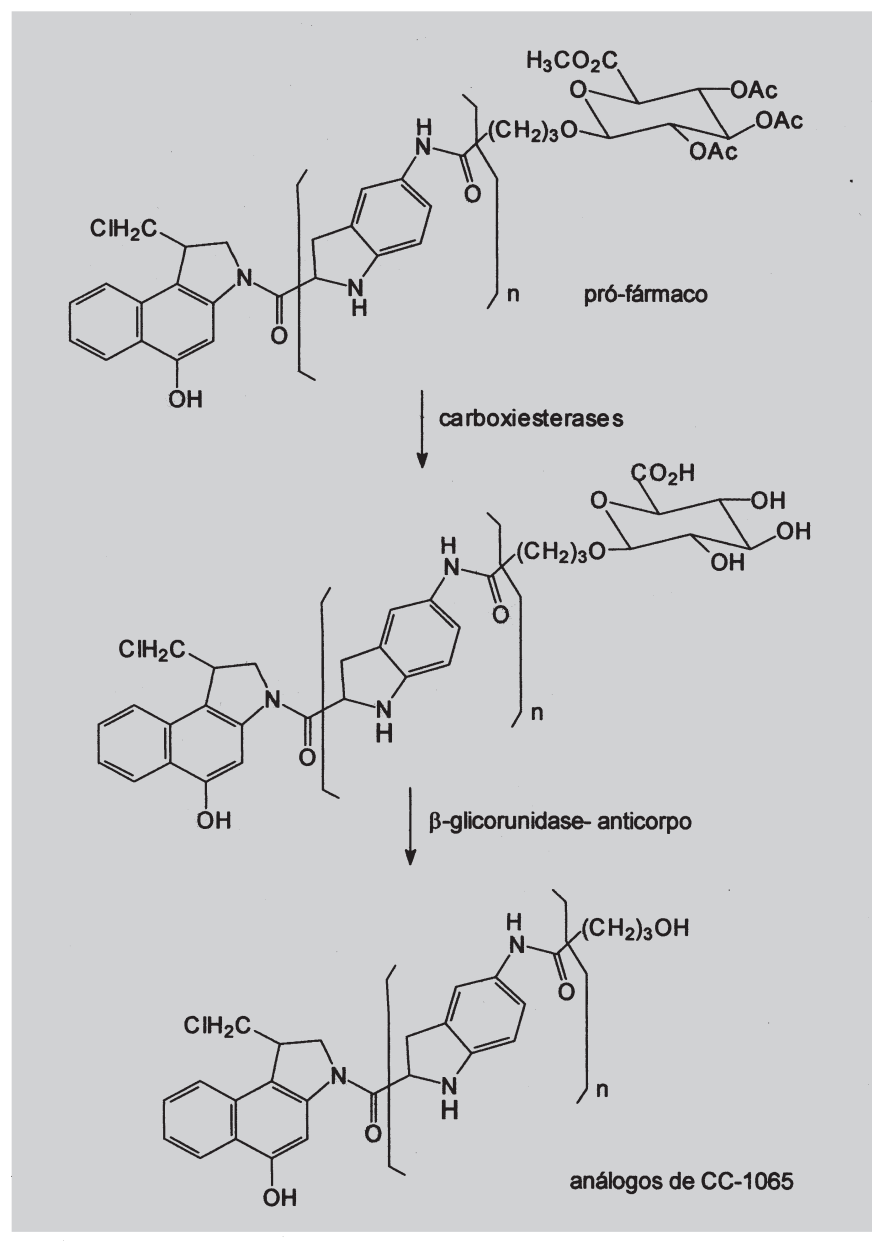

FIGURA 43 - Conversão proposta dos pró-fármacos análogos de CC-1065 em sistema ADEPT-glicuronidase (Wang et al., 2003).

Sagnou e colaboradores, em 2000, sintetizaram três pró-fármacos (PBD) $N^{10}$-(4-nitrobenzil)carbamato protegidos e avaliados para o emprego em ADEPT e GDEPT, utilizando como enzima ativadora a nitrorredutase (NR). O pró-fármaco DC-81 9a (Figura 46) mostrou atividade 100 vezes maior contra o adenocarcinoma humano.

Estudo de relação estrutura-atividade (REA) foi realizado com derivados aziridinilnitrobenzamidas (Figura 46) para utilização em sistema GDEPT ativados por nitrorredutases (Helsby et al., 2004).

\section{OUTROS SISTEMAS SELETIVOS}

\section{ODDS - Sistema de liberação osteotrópica de fármacos}

Embora muitas formas de pró-fármacos tenham sido desenvolvidas, o tecido ósseo ainda permanecia 


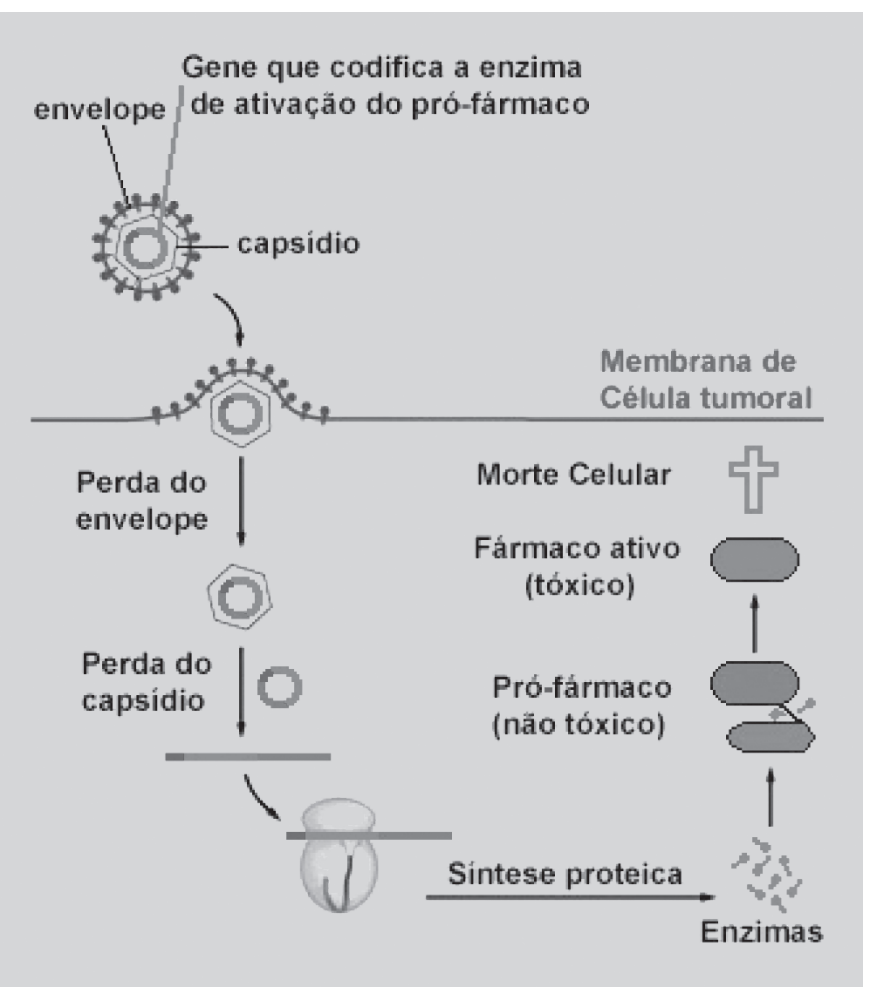

FIGURA 44 - Representação esquemática do conceito de VDEPT.

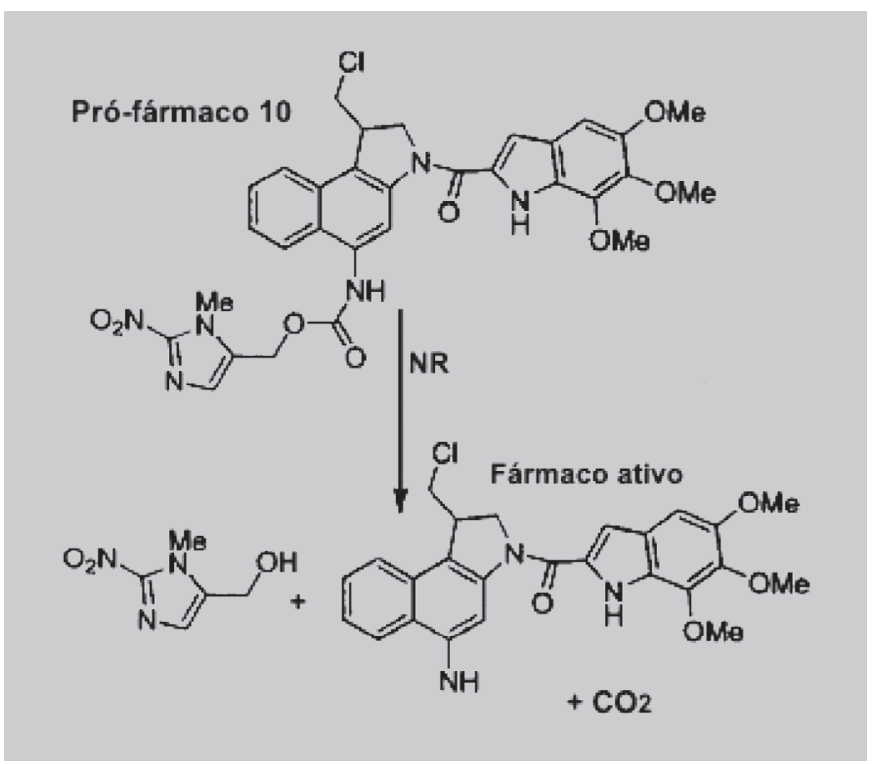

FIGURA 45 - Ativação enzimática do pró-fármaco por meio de nitrorredutase (NR) (Hay et al.., 1999).

como um alvo limitado devido às suas propriedades biológicas e à falta de um sistema circulatório ósseo semelhante ao de outros tecidos (Hirabayashi et al., 2001; Castro et al., 2004).

Um novo e promissor sistema de liberação de fármacos para atingir o tecido ósseo via pró-fármacos foi

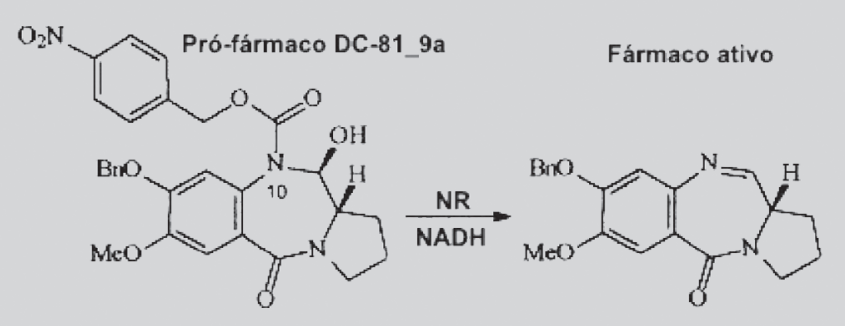

FIGURA 46 - Ativação enzimática do pró-fármaco DC81_9a, por meio de (NR) (Sagnou et al., 2000).

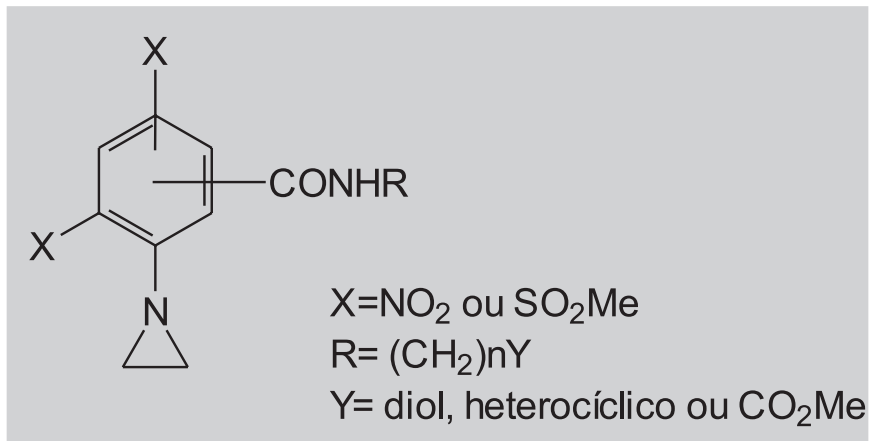

FIGURA 47 - Derivados aziridinilnitrobenzamidas para utilização em sistema GDEPT (Helsby et al., 2004).

proposto, o qual utiliza os bifosfonatos como transportadores (Figura 48) (Fujisaki et al., 1995; Hirabayashi et al., 2001; Castro et al., 2004).

Os bifosfonatos constituem-se em classe de compostos sintéticos estruturalmente relacionados ao pirofosfato, modulador endógeno na homeostase do cálcio nos ossos (Hirabayashi, Fujisaki, 2003; Castro et al., 2004). Estes derivados são utilizados clinicamente em diversas disfunções metabólicas ósseas, como na doença de Paget, hipercalcemia maligna, metástase óssea e osteoporose (Hirabayashi et al., 2001). Possuem alta afinidade pela hidroxiapatita e os tecidos calcificados representam os principais alvos de seu acúmulo após a administração. Utilizando a propriedade de tropismo ósseo dos bifosfonatos, o sistema ODDS faz com que a liberação de fármacos nas estruturas ósseas ou na medula óssea torne-se possível (Hirabayashi et al., 2001; Hirabayashi, Fujisaki, 2003; Castro et al., 2004).

Uma classe terapêutica já testada por esse sistema foi a dos antiinflamatórios não-esteróides (AINEs) contra artrite induzida em ratos. Constatou-se a alta potência, baixa toxicidade e necessidade de um menor número de administração do pró-fármaco em relação ao fármaco matriz (diclofenaco), concluindo-se que o sistema ODDS do diclofenaco é promissor (Figura 49) (Hirabayashi et al., 2001). 


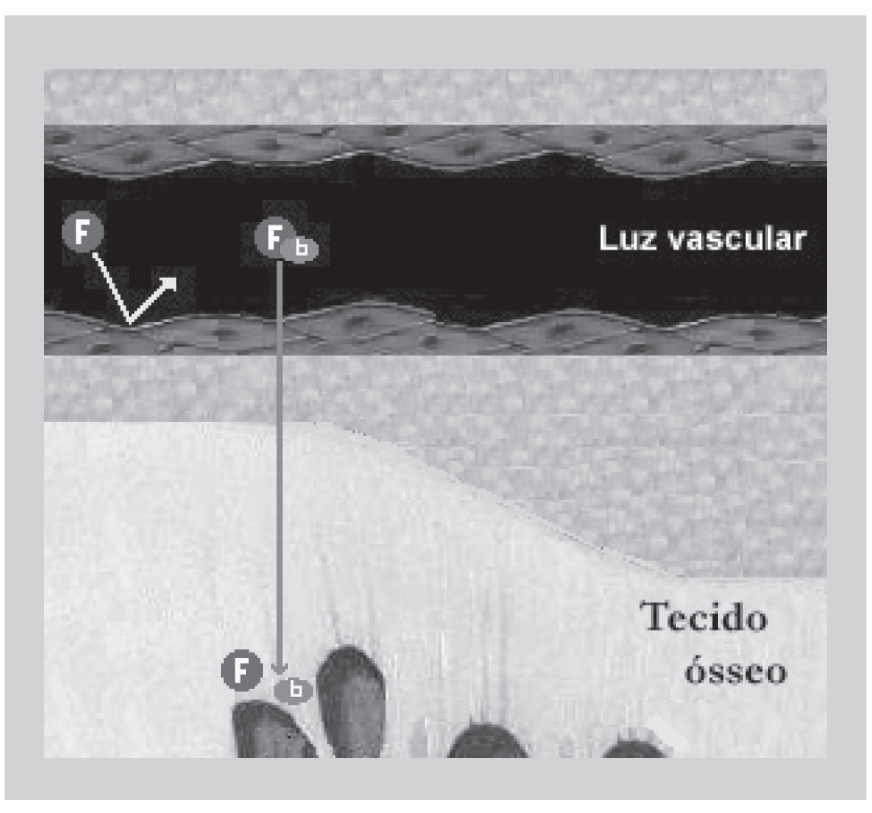

FIGURA 48 - Representação esquemática do conceito de ODDS. Fármaco (F); transportador bifosfonato (b).

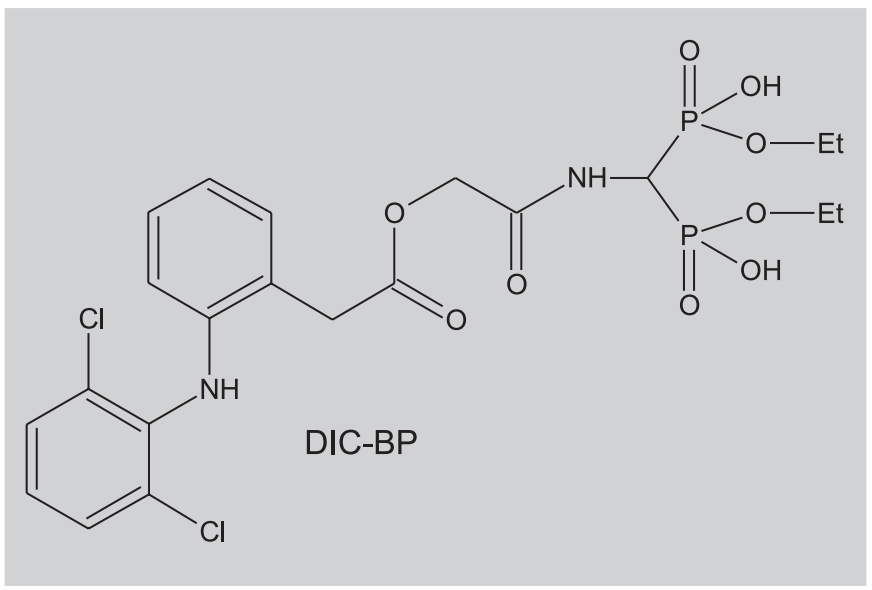

FIGURA 49 - Pró-fármaco do diclofenaco com bisfosfonato (Hirabayashi et al., 2001).

\section{CONCLUSÃO}

A latenciação tem se mostrado ferramenta útil na busca por fármacos, sobretudo com propriedades farmacocinéticas aprimoradas, como alternativa terapêutica para muitas doenças, tanto aquelas provocadas por agentes invasores e neoplasias, como as derivadas de distúrbios funcionais do organismo. É importante salientar que, a despeito de se dispor na atualidade do auxílio de métodos computacionais para a triagem de coleções de número significativamente alto de estruturas com provável ação biológica, muitas das selecionadas, por não apresentarem propriedades farmacêuticas e/ou farmacocinéticas adequadas, são descartadas no prosseguimento dos estudos de descoberta de novos protótipos bioativos. Nesse particular, não raro, o problema diz respeito a coeficiente de partição inadequado, que prejudica a absorção e, por conseguinte, biodisponibilidade que permita ao ligante atingir o receptor específico para a atividade esperada. Problemas dessa natureza podem ser, convenientemente, solucionados com o planejamento de pró-fármacos, com grande probabilidade de sucesso. Por outro lado, por meio desse processo, e com base nos avanços da biotecnologia e da genômica, é possível, na atualidade, dispor de formas latentes mais avançadas, que visem à seletividade de ação desses mesmos ligantes, cuja distribuição errática implica concentração ineficaz ao nível do receptor, com os efeitos indesejáveis decorrentes na atuação em sistemas não-específicos. Concluise daí que o uso de metodologia altamente complexa e potente, como a computacional, não pode prescindir de processos aparentemente mais simples, como a latenciação.

Os estudos em processos mais avançados de latenciação têm se focalizado na área de antineoplásicos, em razão da alta especificidade que se exige dos fármacos dessa classe. Contudo, é necessário se estender esses estudos para doenças consideradas negligenciadas, como endemias tropicais e também a tuberculose, com vistas à descoberta de quimioterápicos mais eficazes que aqueles disponíveis. Tais doenças, por afetarem populações de países pobres, sem recursos para a aquisição de medicamentos dessa natureza, não despertam interesse por parte do segmento industrial, especialmente, as indústrias multinacionais. Temos trabalhado em planejamento de pró-fármacos e fármacos dirigidos de antimaláricos, leishmanicidas, antichagásicos e tuberculostáticos, com o objetivo de obter derivados com atividade aprimorada e com seletividade de ação.

Os avanços aqui apresentados de forma resumida constituem-se em exemplo da multidisciplinaridade envolvida no planejamento de pró-fármacos e outras formas latentes, por meio do processo da latenciação. Assim, conhecimentos relacionados às áreas biológicas, como Imunologia, Enzimologia, Histologia, Biologia Molecular, além de Farmacologia, associados àqueles das áreas exatas, como Química Orgânica, Física e Físico-química, para citar alguns, e que fazem parte da Química Farmacêutica ou Medicinal, são necessários para tornar possível o uso de sistemas altamente seletivos, como ADEPT, GDEPT/VDEPT, ODDS, e outros que virão, certamente, no futuro. 


\section{ABSTRACT}

\section{Latentiation and advanced drug transport forms}

This is a review about the molecular modification process, called latentiation, or prodrug design, focusing the progress in the prodrug approach using macromolecules as carriers and drug target systems as: PDEPT ( Polymer-Directed Enzyme Prodrug Therapy); PELT (Polymer-Enzyme Liposome Therapy); $\boldsymbol{C D S}$ (Chemical Delivery System); ADEPT(Antibody-Directed Enzyme Prodrug Therapy; GDEPT/VDEPT (Gene-Directed Enzyme Prodrug Therapy/Virus-Directed Enzyme Prodrug Therapy and ODDS (Osteotropic Drug Delivery System) and LEAPT (Lectin-Directed EnzymeActivated Prodrug Therapy).

UNITERMS: Latentiation. Prodrug design. Macromolecular carriers. Drug target systems.

\section{REFERÊNCIAS BIBLIOGRÁFICAS}

ALLEN, L. S.; RONALD, C. T.; JEROME, C. B.; JAMES, G. D., III; MILOS, S. A. new prodrug of paclitaxel: synthesis of Protaxel. Anti-Cancer Drugs, v.12, p. 305-313, 2001.

ANAND, B. S.; HILL, J. M.; DEY, S.; MARUYAMA, K.; BHATTACHARJEE, P. S.; MYLES, M. E.; NASHED, Y. E.; MITRA, A. K. In vivo antiviral efficacy of a dipeptide acyclovir prodrug, val-valacyclovir, against HSV-1 epithelial and stromal keratitis in the rabbit eye model. Invest. Ophthalmol. Vis. Sci. , v.44, p. 2529-2534, 2003.

ANAND BS, KATRAGADDA, S., MITRA AK. Pharmacokinetics of novel dipeptide ester prodrug of acyclovir following oral administration:intestinal absortion and liver metabolism. J. Pharmacol. Exp. Ther. Jun 29, DOI:10.1124/jpet.104.069997, 2004.

AVIVA, E.; AMNON, H.; ELI, B.; IVAN, S. A.; JUKKA, M.; NAAMA, E.; EL HANANY-ROZEN, N.; GAL, W.; DAVID, S.; IRITH, G.; HAGIT, C.; SOILI, T.; GORDON, L. A.; GERSHON, G. A peptide prodrug approach for improving bisphosphonate oral absorption. J. Med. Chem., v.43, p.3641-3652, 2000.
BAKER, W. R.; CAI, S.; DIMITROFF, M.; FANG, L.; HUH, K. K.; RYCKMAN, D. R.; SHANG, X.; SHAWAR, R. M.; THERRIEN, J. H. A prodrug approach toward the development of water soluble fluoroquinolones and structure - activity relationships of quinoline-3-carboxylic acids. J. Med. Chem., v. 47, p. 4693-4709, 2004.

BODOR, N.; FARAG, H. H.; POLGAR, .A tryptamine analog with high affinity to the heart tissues is a potential antiarrhythmic agent. J. Pharm. Pharmacol.., v 53 , p. 889-894, 2001.

BODOR, N.; ABDELALIM, A. M. Improved delivery through biological membranes XIX: Novel redox carriers for brain-specific chemical delivery systems. J. Pharm. Sci., v.74, p.241-245, 1985.

BOUCHER P. M.; CASTEL, B.; OKUHARA, Y. Spin excitations in light nuclei: Effect of projectile energy. Phys. Rev. C. Nucl. Phys., v.40, p. 453-455, 1989.

BOUVIER E, THIROT S, SCHMIDT F, MONNERET C. First enzymatically activated Taxotere prodrugs designed for ADEPT and PMT. Bioorg. Med. Chem., v. 1, p. 96977, 2004.

BOUVIER E, THIROT S, SCHMIDT F, MONNERET C.A new paclitaxel prodrug for use in ADEPT strategy. Org. Biomol. Chem., v. 7, p. 3343-52, 2003.

BREWSTER, M. E.; ANDERSON, W.R.; WEBB, A.I.; PABLO, L.M.; MEINSMA, D.; MORENO, D.; DERENDORF, H.; BODOR, N.; POP, E. Evaluation of a brain-targeting zidovudine chemical delivery system in dogs. Antimicrob. Agents Chemother., v.41, p.122128,1997

BROWN, S.B.; BROWN, E. A.; WALKER, I. The present and future role of photodynamic therapy in cancer treatment. Lancet Oncol., v.5, p.497-508, 2004.

BUNDGAARD, H., ed. Prodrug design. Amsterdam: Elsevier, $1985.360 \mathrm{p}$.

CARL, P. L.; CHAKRAVARTY, P. K.; KATZENELLENBOGEN, J. A. E.; WEBER, M. J. Protease-activated "prodrugs" for cancer chemotherapy. Proc. Natl. Acad. Sci. USA, v.77, p.2224-2228, 1980. 
CARVALHO, P.B.; RAMOS, D. C.; COTRIM, P.C.; FERREIRA, E.I. Synthesis and in vitro evaluation of potential anti-leishmanial targeted drugs of pyrimethamine. J. Pharm. Sci., v.92, p.2109-2116, 2003.

CASTRO, L. F.; SILVA, A.T. A.; FERREIRA, A.; FERREIRA, E. I.; CHUNG, M. C. Bifosfonatos como transportadores osteotrópicos de fármacos dirigidos. Quim. Nova, v.27, p. 456-460, 2004.

CHAKRAVARTY, P. K.; CARL, P. L.; WEBER, M. J.; KATZENELLENBOGEN, J. A. Plasmin-activated prodrugs for cancer chemotherapy. 1. Synthesis and biological activity of peptidylacivicin and peptidylphenylenediamine mustard. J. Med.Chem., v.26, p.633-638, 1983.

CHARPIOT B, BITSCH F, BUCHHEIT KH, CHANNEZ P, MAZZONI L, MUELLER T, VACHIER I, NAEF R Disease activated drugs: a new concept for the treatment of asthma. Bioorg. Med. Chem., v 9, p.1793-1805, 2001.

CHEN, X.; WU, B.; WANG, P. G. Glucuronides in anti-cancer therapy. Curr. Med. Chem. Anti-Cancer Agents, v.3, p.139-150, 2003.

CHOI, J. S.; JO, B. W. Enhanced paclitaxel bioavailability after oral administration of pegylated paclitaxel prodrug for oral delivery in rats. Int. J. Pharm., v.6 p. 221-227, 2004.

CHUNG, M. C.; GUIDO, R. .V.; MARTINELLI, T. F.; GONCALVES, M. F.; POLLI, M. C.; BOTELHO, K. C.; VARANDA, E. A.; COLLI, W.; MIRANDA, M. T.; FERREIRA, E. I. Synthesis and in vitro evaluation of potential antichagasic hydroxymethylnitrofurazone (NFOH-121): a new nitrofurazone prodrug. Bioorg. Med. Chem., v. 3, p.4779-4783, 2003.

CHUNG, M. C. Planejamento e síntese de pró-fármacos recíprocos de nitrofural e primaquina potencialmente antichagásicos. São Paulo, 1996. 196 p. [Tese de doutorado. Faculdade de Ciências Farmacêuticas. Universidade de São Paulo].

CHUNG, M. -C.; GONÇALVES, M. F.; COLLI, W.; FERREIRA, E. I.; MIRANDA, M. T. Synthesis and in vitro evaluation of potential antichagasic dipeptide prodrugs of primaquine. J. Pharm. Sci., v.86, p.1127-31, 1997.
CHUNG, M.-C.; FERREIRA, E. I. O processo de latenciação no planejamento de fármacos. Quím. Nova, v.22, p.75-84, 1999.

CLERICI, C.; GENTILI, G.; BOSCHETTI, E.; SANTUCCI, C.; ABURBEH, A. G.; NATALINI, B.; PELLICCIARI, R.; MORELLI, A. Amino acid derivatives of 5-ASA as novel prodrugs for intestinal drug delivery. Dig. Dis. Sci., v.39, p.2601-2606, 1994.

DETTY, M. R.; GIBSON, S. L; WAGNER, S. J. Current clinical and preclinical photosensitizers for use in photodynamic therapy. J. Med. Chem., v. 47, p.3897-3915, 2004.

DEVY, L.; DE GROOT, F. M.; BLACHER, S.; HAJITOU, A.; BEUSKER, P. H.; SCHEEREN, H. W.; FOIDART, J. M.; NOEL, A. Plasmin-activated doxorubicin prodrugs containing a spacer reduce tumor growth and angiogenesis without systemic toxicity. FASEB J., v.18, p. 565-567, 2004.

DUNCAN, R. The dawning era of polymer therapeutics. Nat. Rev. Drug Discov., v. 2, p. 347-360, 2003.

DUNCAN, R.; GAC-BRETON, S.; KEANE, R.; MUSILA, R.; SAT, Y. N.; SATCHI, R.; SEARLE, F. Polymer-drug conjugates, PDEPT and PELT: basic principles for design and transfer from the laboratory to clinic. J. Controlled Release, v.74, p.135-146, 2001.

DUVAZ, N.; SPRINGER, C. J. Antibody enzyme prodrug therapy (ADEPT): a review. Adv. Drug Delivery Rev., v.26, p.151-172, 1997.

ERION, M. D.; VAN POELJE, P. D.; MACKENNA, D. A.; COLBY, T. J.; MONTAG, A.; FUJITAKI, J. M.; LINEMEYER, D. L.; BULLOUGH, D. A. Livertargeted drug delivery using HepDirect ${ }^{\mathrm{TM}}$ prodrugs. $J$. Pharmacol. Exp. Ther., Aug 31, DOI:10.1124/ jpet.104.07593, 2004.

ETTMAYER, P.; AMIDON, G. L.; CLEMENT, B.; TESTA, B. Lessons learned from marketed and investigational prodrugs. J. Med. Chem., v. 47, p. 2393-2404, 2004.

FARAG, H. H.; WU, W. M.; BARROS, M. D.; SOMOGYI, G.; PROKAI, L.; BODOR, N. Ocular-specific chemical delivery systems of betaxolol for safe local treatment of glaucoma. Drug Des. Discov., v. 15, p. 117-130, 1997. 
FERRY, D. R.; SEYMOUR, L.W.; ANDERSON, D.; HESSELWOOD, S.; JULYAN, P.; BOIVIN, C.; POYNER R.; GUEST, P.; DORAN, J.; KERR, D. J. Phase I trial of liver-targeted HPMA copolymer doxorubicin PK2, pharmacokinetics, spect imaging of ${ }^{123}$ I-PK2 and activity in hepatoma. Br. J. Cancer, v. 80, p.21, 1999.

FRANCIS, R J.; SHARMA, S. K.; SPRINGER, C.; GREEN, A. J.; HOPE-STONE, L. D.; SENA, L.; MARTIN, J.; ADAMSON, K. L.; ROBBINS, A.; GUMBRELL, L.; O'MALLEY, D.; TSIOMPANOU, E.; SHAHBAKHTI, H.; WEBLEY, S.; HOCHHAUSER, D.; HILSON, A. J.; BLAKEY, D.; BEGENT, R. H. A phase I trial of antibody directed enzyme prodrug therapy (ADEPT) in patients with advanced colorectal carcinoma or other CEA producing tumours. Br. J. Cancer, v 87, p. 600-607, 2002.

FRIIS, G..J.; BUNDGAARD, H. Design and application of prodrugs. In: KROGSGAARD-LARSEN, P., LILJEFORS, T., MADSEN, U., eds. A textbook of drug design and development. Amsterdam: Harwood Academic, 1996. p. 351-385.

FUJISAKI, J.; TOKUNAGA, Y.; TAKAHASHI, T.; HIROSE, T.; SHIMOJO, F.; KAGAYAMA, A.; HATA, T. Osteotropic drug delivery system (ODDS) based on bisphosphonic prodrug. I: synthesis and in vivo characterization of osteotropic carboxyfluorescein. $J$. Drug Target, v.3, p. 273-282, 1995.

GOLD, M. H.; GOLDMAN, M. P. 5-aminolevulinic acid photodynamic therapy: where we have been and where we are going. Dermatol. Surg., v.30, p.1077-1083, 2004.

GREEN, N. K.; KERR, D. J.; MAUTNER, V.; HARRIS, P. A.; SEARLE, P. F. The nitroreductase/CB1954 enzymeprodrug system. Methods Mol. Med., v 90, p. 459-477, 2004.

GROVE, J. I.; SEARLE, P. F.; WEEDON, S. J.; GREEN, N. K.; MCNEISH, I. A.; KERR, D. J. Virus-directed enzyme prodrug therapy using CB1954. Anticancer Drug Des., v.14, p.461-472, 1999.

GROVE, J. I.; SEARLE, P. F.; WEEDON, S. J.; GREEN, N. K.; MCNEISH, I. A.; KERR, D. J. GÜIDO, R. V. C.; FERREIRA, E. I.; NASSUTE, J. C.; VARANDA, E. A.; CHUNG, M.C. Diminuição da atividade mutagênica do prófármaco NFOH-121 em relação ao nitrofural (nitrofurazona). Rev. Ciên. Farm., v. 22, p. 319-333, 2001.
HAN, H. K.; AMIDON, G. L. Targeted prodrug design to optimize drug delivery. AAPS Pharm. Sci., v.2., p.E6, 2000.

HARIKRISHNA, D.; RAO, A. R.; KRISHNA, D. R. Selective activation of anthracycline prodrugs for use in conjunction with ADEPT. Drug News Perspect., v.16, p.309-318, 2003.

HAY, M. P.; SYKES, B. M.; DENNY, W. A.; WILSON, W. R. A 2-nitroimidazole carbamate prodrug of 5-amino-1(chloromethyl)-3-[(5,6,7-trimethoxyindol-2-il)carbonyl]1,2-dihydro-3H-benz[e]indole (AMINO-SECO-CBITMI) for use with ADEPT and GDEPT. Bioorg. Med.Chem., v.9, p.2237-2242, 1999.

HEINIS, C.; ALESSI, P.; NERI, D. Engineering a thermostable human prolyl endopeptidase for antibodydirected enzyme prodrug therapy. Biochemistry, v. 43, p. 6293-6303, 2004.

HELSBY, N. A.; ATWELL, G. J.; YANG, S.; PALMER, B. D.; ANDERSON, R. F.; PULLEN, S. M.; FERRY, D. M.; HOGG, A.; WILSON, W. R.; DENNY, W. A. Aziridinyldinitrobenzamides: synthesis and structureactivity relationships for activation by E. coli nitroreductase. J. Med. Chem., v 47, p 3295-3307, 2004.

HIRABAYASHI, H.; FUJISAKI, J. Bone-Specific Drug Delivery System. Approaches via chemical modification of bone-seeking agents. Clin. Pharmacokinet., v.42, p. 1319-1330, 2003.

HIRABAYASHI, H.; TAKAHASHI, T.; FUJISAKI, J.; MASUNAGA, T.; SATO, S.; HIROI, J.; TOKUNAGA, Y.; KIMURA, S.; HATA, T. Bone-specific delivery and sustained release of diclofenac, a non-steroidal antiinflammatory drug, via bisphosphonic prodrug based on the Osteotropic Drug Delivery System (ODDS). $J$. Controlled Release, v.70, p.183-191, 2001.

HOUBA, P. H. J.; LEENDERS, R. G. G.; BOVEN, E.; SCHEEREN, J. W.; PINEDO, H. M.; HAISMA, H. J. Characterization of novel anthracycline prodrugs activated by human b-glucuronidase for use in antibody-directed enzyme prodrug therapy. Biochem. Pharmacol., v.52. p.455-463, 1996.

HULL, D.; CHESTER, M. Gene therapy trials: a patient pathway. Nurs. Stand. , v.17, p. 39-42, 2002. 
JAIN, R. K. Transport of molecules across tumor vasculature. Cancer Metastasis Rev., v.6, p.559-593, 1987.

JARKKO, R.; TAPIO, N.; HANNU, T.; JOUKO, V.; JUKKA, G.; KRISTA, L.; TOMI, J. Synthesis and in vitro evaluation of novel morpholinyl and methylpiperazinylacyloxyalkyl prodrugs of 2-(6-methoxy2-naphthyl)propionic acid (naproxen) for topical drug delivery. J. Med. Chem., v.43, p.1489-1494, 2000.

JOHANSSON, E.; PARKINSON, G. N.; DENNY, W. A.; NEIDLE, S. Studies on the nitroreductase prodrugactivating system. Crystal structures of complexes with the inhibitor dicoumarol and dinitrobenzamide prodrugs and of the enzyme active form. J. Med. Chem., v. 46, p. 40094020, 2003.

KERR, D. J.; YOUNG, L. S.; SEARLE, P. F.; MCNEISH, I. A. Gene directed enzyme prodrug therapy for cancer. Adv. Drug Deliv. Rev., v.26, p.173-184, 1997.

LIAO, Y.; WANG, B. Substituted coumarins as ester-sensitive prodrug moieties with improved release rates. Bioorg. Med. Chem., v.9, p.1975-1800, 1999.

LITTLE, R.; BAILEY, D.; BREWSTER, M.; ESTES, K.; CLEMMONS, R.; SAAB, A.; BODOR, N. Improved delivery through biological membranes XXXIII. Brain enhanced delivery of azidothymidine (AZT). $J$. Biopharm. Sci., v.1, p.1-18, 1990.

MANN, K. K.; REPHAELI, A.; COLOSIMO, A. L.; DIAZ, Z.; NUDELMAN, A.; LEVOVICH, I.; JING, Y.; WAXMAN, S.; MILLER, W. H. JR. A retinoid/butyric acid prodrug overcomes retinoic acid resistance in leukemias by induction of apoptosis. Mol. Cancer Res., v.12 p. 903-912, 2003.

MATSUMURA, Y. E.; MAEDA, H. A new concept for macromolecular therapeutics in cancer chemotherapy: mechanism of tumoritropic accumulation of proteins and the antitumor agent smancs. Cancer Res., v.46. p.6387$6392,1986$.

NASHED, Y. E.; MITRA, A. K. Synthesis and characterization of novel dipeptide ester prodrugs of acyclovir. Spectrochim. Acta Mol. Biomol. Spectrosc., v. 59, p. 2033-2039, 2003.
NASSUTE, J.C.; LONGO, M. C.; MENEGON, R. F.; RIBEIRO, Y.A.; CHUNG, M. C. Atividade antiedema do pró-fármaco polimérico $\mathrm{PDC}-70$ derivado de diclofenaco. Rev. Ciênc. Farm., v. 23, p. 2002.

NICOLAOU, K. C.; RIEMER, C.; KERR, M. A.; RIDEOUT, D.; WRASIDLO, W. Design, synthesis and biological activity of protaxols. Nature, v. 364. p. 464-466, 1993.

NISHIDA, K.; KIDO, M.; SASAKI, H. E NAKAMURA, J. Pharmacokinetic analysis of in vivo metabolism of amino acid or dipeptide conjugates of salicylic acid in rabbit intestinal microorganisms. J. Pharm. Res., v.11, p.160-174, 1994.

NISHIKAWA, M.; KAMIJO, A.; FUJITA, T.; TAKAKURA, Y.; SEZAKI, H.; HASHID, M. Synthesis and pharmacokinetics of a new liver-specific carrier, glycosylated carboxymethyl-dextran, and its application to drug targeting. Pharm. Res., v. 10, p. 1253-1261, 1993.

O'CONNOR, S. W. E.; BALE, W. F. Accessibility of circulating immunoglobulin $\mathrm{G}$ to the extravascular compartment of solid rat tumors. Cancer Res., v.44, p.3719-3723, 1984.

OH, J. E.; NAM, Y. S.; LEE, K. H.; PARK, T. G. Conjugation of drug to poly(D,L-lactic-co-glycolic acid) for controlled release from biodegradable microspheres. J. Controlled Release. V. 57, p. 269-280, 1999.

OKUNO, S.; HARADA, M.; YANO, T.; YANO, S.; KIUCHI, S.; TSUDA, N.; SAKAMURA, Y.; IMAI, J.; KAWAGUCHI, T.; TSUJIHARA, K. Complete regression of xenografted human carcinomas by camptothecin analogue-carboxymethyl dextran conjugate (T-0128). Cancer Res.,v.60. p.2988-2995, 2000.

PALMER, D. H.; MAUTNER, V.; MIRZA, D.; OLIFF, S.; GERRITSEN, W.; VAN DER, S. I. J. P. JR; HUBSCHER, S.; REYNOLDS, G.; BONNEY, S.; RAJARATNAM, R.; HULL, D.; HORNE, M.; ELLIS, J.; MOUNTAIN, A.; HILL, S.; HARRIS, P.A.; SEARLE, P. F.; YOUNG, L. S.; JAMES, N. D.; KERR, D. J. Virus-directed enzyme prodrug therapy: intratumoral administration of a replication-deficient adenovirus encoding nitroreductase to patients with resectable liver cancer. J. Clin. Oncol., v. 22, p.1546$1552,2004$. 
PERIOLI, L.; AMBROGI, V.; BERNARDINI, C.; GRANDOLINI, G.; RICCI, M.; GIOVAGNOLI. S.; ROSSI C. Potential prodrugs of non-steroidal antiinflammatory agents for targeted drug delivery to the CNS. Eur. J. Med. Chem., v.39, p. 715-727, 2004.

PROKAI, L.; PROKAI-TATRAI, K.; BODOR N. Targeting drugs to the brain by redox chemical delivery systems. Med. Res. Rev., v. 20, p.367-416, 2000.

REDDY, I. K.; VAITHIYALINGAM, S. R.; KHAN, M. A.; BODOR, N. S. Design, in vitro stability, and ocular hypotensive activity of t-butalone chemical delivery systems. J. Pharm. Sci. v 90, p. 1026-1033, 2001.

SAGNOU, M. J.; HOWARD, P. W.; GREGSON, S. J.; ENO-AMOOQUAYE, E.; BURKE,P. J.; THURSTON, D. E. Design and synthesis of novel pyrrolobenzodiazepine (PBD) prodrugs for ADEPT and GDEPT. Bioorg. Med. Chem. Lett., v.10, p. 2083-2086, 2000

SATCHI-FAINARO, R.; HAILU, H.; DAVIES, J. W.; SUMMERFORD, C.; DUNCAN, R. PDEPT: polymerdirected enzyme prodrug therapy. 2. HPMA copolymerbeta-lactamase and HPMA copolymer-C-Dox as a model combination. Bioconjug. Chem., v. 14, p. 797-804, 2003.

SCARLATO, A. E.; ALVES, I. C.; CARDOSO, R. P. A.; ANDRADE JUNIOR, H. F.; FERREIRA, E. I. Potential antimalarial targeted drugs of primaquine with specific delivery in liver. Congress of the American Association of Pharmaceutical Scientists,1999.

SENTER, P. D.; SPRINGER, C. J. Selective activation of anticancer prodrugs by monoclonal antibody-enzyme conjugates. Adv. Drug Deliv. Rev., v.53, p.247-264, 2001.

SHARMA, V.; KHAN, M. S. Prodrugs and mutual prodrugs: synthesis of some new pyrazolone and oxadiazole analogues of a few non-steroidal anti-inflammatory drugs. Pharmazie, v. 58, p. 99-103, 2003.

SILVA, A. T. A.; CHUNG, M. C.; CASTRO, L. F.; GÜIDO, R. V. C.; FERREIRA, E. I. Advances in prodrug design. Mini Rev. Med. Chem., 2005. (in press).

SILVA, M. Tuberculostáticos potenciais: pró-fármacos formadores de micelas derivados de isoniazida, rifampicina e pirazinamida. São Paulo, 2001. 166 p. [Tese de doutorado. Faculdade de Ciências Farmacêuticas. Universidade de São Paulo].
SILVA, M.; LARA, A. S.; LEITE, C. Q.; FERREIRA, E. I. Potential tuberculostatic agents: micelle-forming copolymer poly(ethylene glycol)-poly(aspartic acid) prodrug with isoniazid. Arch. Pharm. , v.334, p. 189-193, 2001.

SINGH, G.; SHARMA, P.D. Mutual prodrugs - a recent trend in prodrug design. Indian J. Pharm. Sci., v.56, n.3, p.6979, 1994.

SKOBLOV, Y.; KARPENKO, I.; SHIROKOVA, E.; POPOV, K.; ANDRONOVA, V.; GALEGOV G.; KUKHANOVA, M. Intracellular metabolism and pharmacokinetics of 5'-hydrogenphosphonate of 3'-azido2',3'-dideoxythymidine, a prodrug of 3'-azido-2',3'dideoxythymidine. Antiviral Res., v. 63, p. 107-113, 2004

SOMOGYI, G.; BUCHWALD, P.; BODOR, N. Targeted drug delivery to the central nervous system via phosphonate derivatives (anionic delivery system for testosterone). Pharmazie, v.57, p.135-137, 2002.

SOMOGYI G, BUCHWALD P, BODOR N. Metabolic properties of phosphonate esters. Pharmazie, v. 59, p. 378381,2004 .

STEFFANSEN, B.; NIELSEN, C. U.; BRODIN, B.; ERIKSSON, A. H.; ANDERSEN, R.; FROKJAER, S. Intestinal solute carriers: an overview of trends and strategies for improving oral drug absorption. Eur. $J$. Pharm. Sci., v.21, p.3-16, 2004.

TAKAKURA, Y.; FUJITA, T.; HASHIDA, M. E SEZAKI, $H$. Disposition characteristics of macromolecules in tumor-bearing mice. Pharm. Res., v.7, p.339-346, 1990.

TAKAKURA, Y.; HASHIDA, M. Macromolecular drug carrier systems in cancer chemotherapy: macromolecular prodrugs. Crit. Rev. Oncol. Hematol., v. 18, p.207-231, 1995.

TAKAKURA, Y.; TAKAGI, A.; HASHIDA, M.; SEZAKI, $\mathrm{H}$. Disposition and tumor localization of mitomycin Cdextran conjugates in mice. Pharm. Res.,v.4. p.293-300, 1987.

TAPFER, M. K.; SEBESTYEN, L.; KURUCZ, I.; HORVATH, K.; SZELENYI, I.; BODOR, N. New evidence for the selective, long-lasting central effects of the brain-targeted estradiol, Estredox. Pharmacol. Biochem. Behav., v.77, p.423-429, 2004. 
TESTA, B.; CALDWELL, J. Prodrugs revisited: the "ad hoc" approach as a complement to ligand design. Med. Res. Rev., v. 16, p. 233-241, 1996.

THOMSEN, A. E.; FRIEDRICHSEN, G. M.; SORENSEN,A. H.; ANDERSEN, R.; NIELSEN, C. U.; BRODIN, B.; BEGTRUP, M.; FROKJAER, S.; STEFFANSEN, B. Prodrugs of purine and pyrimidine analogues for the intestinal di/tri-peptide transporter PepT1: affinity for hPepT1 in Caco2 cells, drug release in aqueous media and in vitro metabolism. J. Controlled Release, v. 86, p. 279-292, 2003.

TROUET, A.; JOLLES, G. Targeting of daunorubicin by association with DNA or proteins: a review. Semin Oncol., v. 11, p. 64-72, 1984.

VABENO, J.; NIELSEN, C. U.; INGEBRIGTSEN, T.; LEJON, T.; STEFFANSEN, B.; LUTHMAN, K. Dipeptidomimetic ketomethylene isosteres as pro-moieties for drug transport via the human intestinal di-/tripeptide transporter hPEPT1: design, synthesis, stability, and biological investigations. J. Med. Chem., v.47, p. 47554765, 2004.

VITOLS, K. S.; HAAG-ZEINO, B.; BAER, T.; MONTEGANO, Y. D.; HUENNEKENS, F. M. Methotrexate-alpha-phenylalanine: optimization of methtrexate prodrug for activation by carboxypeptidase A-monoclonal antibocy conjugate. Cancer Res., v.55, p. 478-481, 1995.

VLIEGHE, P.; CLERC, T.; PANNECOUQUE, C.; WITVROUW, M.; DE CLERCQ, E.; SALLES, J.P.; KRAUS, J. L. Synthesis of new covalently bound kappacarrageenan-AZT conjugates with improved anti-HIV activities. J. Med. Chem., v.45, p.1275-1283, 2002.

WANG, X. Y.; MARTINIELLO-WILKS, R.; SHAW, J. M.; HO, T.; COULSTON, N.; COOKE-YARBOROUGH, C.; MOLLOY, P. L.; CAMERON, F.; MOGHADDAM, M.; LOCKETT, T. J.; WEBSTER, L. K.; SMITH, I. K.; BOTH, G. W.; RUSSELL, P. J. Preclinical evaluation of a prostate-targeted gene-directed enzyme prodrug therapy delivered by ovine atadenovirus. Gene Ther., 2004 (no prelo).

WANG, Y.; YUAN, H.; WRIGHT, S. C.; WANG, H.; LARRICK, J. W. Synthesis and preliminary cytotoxicity study of a cephalosporin-CC-1065 analogue prodrug. BMC Chem. Biol., v.1, p.4, 2001.
WEI, Y.; PEI, D. Activation of antibacterial prodrugs by peptide deformylase. Bioorg. Med. Chem., v.10, p.10731076, 2000.

WERMUTH, C. G. Designing prodrugs and bioprecursors In: , ed. The practice of medicinal chemistry, London: Academic Press, 2003. p. 697-716.

WILLIAMS, D. A., LEMKE, T. L. Foye's principles of medicinal chemistry, 5ed, Baltimore: Lippincott Williams \& Wilkins, 2002. no. páginas

WU, J.; YOON, S. H.; WU, W. M.; BODOR, N. Synthesis and biological evaluations of brain-targeted chemical delivery systems of [Nva2]-TRH. J. Pharm. Pharmacol., v. 54, p. 945-950, 2002.

XU, G.; McLEOD, H. L. Strategies for enzyme/prodrug cancer therapy. Clin. Cancer Res., v.7, p.3314-3324, 2001.

YOKOYAMA, M.; MIYAUCHI, M.; YAMADA, N.; OKANO, T.; SAKURAI, Y.; KATAOKA, K.; INOUE $\mathrm{S}$. Characterization and anticancer activity of micelle-fog polymeric anticancer drug adriamycin-conjugateed poly(ethylene glycol)-poly(aspartic acid) block copolymer. Cancer Res., v.50. p.1693-1700, 1990.

YOKOYAMA, M.; OKANO, T.; SAKURAI, Y.; EKIMOTO, H.; SHIBAZAKI, C.; KATAOKA, K. Toxicity and antitumor activity against solid tumors of micelle-forming polymeric anticancer drug and its extremely long circulation in blood. Cancer Res., v.51.p. 3229-3236, 1991.

YURA, H.; YOSHIMURA, N.; HAMASHIMA, T.; AKAMATSU, K.; NISHIKAWA, M.; TAKAKURA, Y.; HASHIDA, M. Synthesis and pharmacokinetics of a novel macromolecular prodrug of tacrolimus (FK506), FK506-dextran conjugate. J. Controlled Release, v.57, p. 87-99, 1999.

ZHENG, A.; WANG, W.; ZHANG, H.; WANG, B. Two new improved approaches to the synthesis of coumarin-based prodrugs. Tetrahedron, v..55, p.4237-4254, 1999.

Recebido para publicação em 20 de novembro de 2003 Aceito para publicação em 16 de junho de 2005 